\title{
Functional annotation of the transcriptome of Sorghum bicolor in response to osmotic stress and abscisic acid
}

\author{
Diana V Dugas', Marcela K Monaco ${ }^{2}$, Andrew Olson², Robert R Klein ${ }^{3}$, Sunita Kumari', Doreen Ware ${ }^{2,4}$ and \\ Patricia E Klein ${ }^{1 *}$
}

\begin{abstract}
Background: Higher plants exhibit remarkable phenotypic plasticity allowing them to adapt to an extensive range of environmental conditions. Sorghum is a cereal crop that exhibits exceptional tolerance to adverse conditions, in particular, water-limiting environments. This study utilized next generation sequencing (NGS) technology to examine the transcriptome of sorghum plants challenged with osmotic stress and exogenous abscisic acid (ABA) in order to elucidate genes and gene networks that contribute to sorghum's tolerance to water-limiting environments with a long-term aim of developing strategies to improve plant productivity under drought.

Results: RNA-Seq results revealed transcriptional activity of 28,335 unique genes from sorghum root and shoot tissues subjected to polyethylene glycol (PEG)-induced osmotic stress or exogenous ABA. Differential gene expression analyses in response to osmotic stress and ABA revealed a strong interplay among various metabolic pathways including abscisic acid and 13-lipoxygenase, salicylic acid, jasmonic acid, and plant defense pathways. Transcription factor analysis indicated that groups of genes may be co-regulated by similar regulatory sequences to which the expressed transcription factors bind. We successfully exploited the data presented here in conjunction with published transcriptome analyses for rice, maize, and Arabidopsis to discover more than 50 differentially expressed, drought-responsive gene orthologs for which no function had been previously ascribed.
\end{abstract}

Conclusions: The present study provides an initial assemblage of sorghum genes and gene networks regulated by osmotic stress and hormonal treatment. We are providing an RNA-Seq data set and an initial collection of transcription factors, which offer a preliminary look into the cascade of global gene expression patterns that arise in a drought tolerant crop subjected to abiotic stress. These resources will allow scientists to query gene expression and functional annotation in response to drought.

\section{Background}

Crop productivity is significantly impacted by abiotic constraints, especially water availability [1]. Given the expanding demand for water by urban populations $[2,3]$, crop productivity in drought-prone environments must be addressed primarily through genetic improvement [1]. The genetic basis of plant adaptation to the environment is complex and includes an extraordinary range of developmental strategies (i.e., cacti, ephemerals, lichens), morphological features (i.e., variation in leaf and root

\footnotetext{
* Correspondence: pklein@tamu.edu

'Department of Horticulture, Texas A\&M University, College Station, TX 77843 , USA

Full list of author information is available at the end of the article
}

system morphology), biochemical mechanisms (i.e., C3/ C4/CAM photosynthesis, osmotic adjustment, dehydrins), and physiological traits (i.e., stomatal regulation, stay-green) (reviewed in [1,4-11]).

Sorghum (Sorghum bicolor L. Moench) is an excellent model for the study of plant response to abiotic stress, particularly drought stress. With the exception of millet, sorghum is the cereal best adapted to water-limited environments and ranks amongst the most drought tolerant of all crops grown in the U.S. [9]. Sorghum's drought tolerance is consistent with its evolution in Africa [12], which resulted in the development of heritable morphological and anatomical characteristics (i.e., C4 photosynthesis, thick leaf wax, deep root system)
C Biomed Central

() 2011 Dugas et al; licensee BioMed Central Ltd. This is an Open Access article distributed under the terms of the Creative Commons Attribution License (http://creativecommons.org/licenses/by/2.0), which permits unrestricted use, distribution, and reproduction in any medium, provided the original work is properly cited. 
that permit sorghum's growth in hot, dry environments. Sorghum also exhibits physiological responses (i.e., osmotic adjustment, stay-green) that allow continued growth under drought, and adaptive mechanisms (i.e., quiescence) that allow extreme drought tolerance.

A challenge presently facing plant scientists is to obtain the molecular knowledge and experimental tools required to identify the network of genes that condition crop adaptation to harsh environments. The interplay between drought and changes in plant gene expression has been intensely studied in numerous species including Arabidopsis [13-22], rice [23-27], maize [28-30], and sorghum [31]. Recently, the metabolic interplay between ABA and other plant hormones was implicated in a variety of plants grown under drought or osmotic stress conditions [32-34]. These studies provide insight into the relationship among drought tolerance, gene networks, and the metabolic pathways conditioning each species response to drought (reviewed in [35-39]).

In the mid-2000's, cDNA microarray experiments were conducted to examine sorghum's response to various abiotic and biotic stresses. These studies included the effects of PEG-induced osmotic stress, exogenous abscisic acid (ABA), salt, wounding (by jasmonic acid JA), and insects (by salicylic acid - SA) [31,40-42]. The recent release of a complete genome sequence for sorghum [43] and the development of SorghumCyc, a metabolic pathways database (http://www.gramene.org/ pathway/sorghumcyc.html), as well as ultra highthroughput sequencing technology (i.e., next generation sequencing or NGS) provide a unique opportunity to obtain a more complete view of the genes and gene networks conditioning abiotic stress tolerance in sorghum.

Herein, we exploited RNA-Seq technology in combination with the sorghum genome sequence [43] and the SorghumCyc metabolic pathways database to characterize the sorghum transcriptome and to reexamine the differential expression of sorghum genes in response to exogenous ABA and osmotic stress. The present results expand on the sorghum cDNA-array analyses of Buchanan et al. [31] by examining the expression of all currently annotated sorghum genes, providing evidence of the interconnectivity of drought-regulated pathways, and discussing the interplay between transcription factors (TFs) and the corresponding cis-acting elements upon which they act. We also employ the sequenced genomes of sorghum, rice, maize, and Arabidopsis to explore orthologous transcripts from genes that exhibit differential expression following ABA treatment and/or osmotic stress across species to investigate the possible evolutionary significance of genes of unknown function in abiotic stress response.

\section{Results and Discussion}

\section{Mapping the Sorghum bicolor Transcriptome}

In 2005, changes in sorghum gene expression due to exogenous ABA treatment and PEG-induced osmotic stress were assayed by cDNA microarray technology [31], and, based on existing EST resources at that time, it was estimated that the sorghum cDNA array consisted of 12,982 unique genes [31]. In 2009, the sorghum draft genome sequence and annotations revealed $\sim 34,500$ genes [43]; upon reexamination of cDNA sequences on the sorghum microarray, we determined that only $\sim 25 \%$ of the reported sorghum genes (8,797 EST-to-unique gene mappings) were spotted on the cDNA array. Due to the limited number of unique genes spotted on the sorghum cDNA microarray, the present study readdresses the changes in sorghum gene expression in response to exogenous $\mathrm{ABA}$ or osmotic stress using a global transcriptome profiling approach.

We conducted RNA-Seq on three independent biological experiments, each one consisting of a pool of paired shoot/root tissues treated with ABA, PEG or their respective controls (Figure 1). A total of 689.5 million reads were generated across all three biological replicates. These sequences were trimmed to $50 \mathrm{bp}$ and aligned to the sorghum genome. Of the total reads, 535.9 million passed purity filtering standards, and, of those, 462.9 million ( $86-87 \%)$ uniquely mapped to the sorghum genome (Figure 2A, Table 1 and Additional File 1). Most of the uniquely mapped RNA-Seq reads aligned to exons $(72 \%)$ with the remainder distributed among introns (3\%), intergenic regions (10\%), and splice junctions (15\%) (Figure $2 \mathrm{~B}$ and Additional File 1). In total, $67.1 \%$ of the 689.5 million collected reads passed filtering and mapped uniquely to the genome, slightly higher than previously published results, which range from $38-60 \%$ [44-47].

An upgrade in the software used for base calling after completion of the second biological replicate resulted in an increase in the overall number of reads collected, emphasizing the need for normalization across runs. Quantile normalization was performed for each run and subsequently across all samples simultaneously (Figure 3) using edgeR [48-50]. The range of reads mapped to a gene was comparable across runs, with the 9 lanes of increased sequence counts displaying a slight increase in median read number per gene (Figure $3 \mathrm{~A}$ and $3 \mathrm{~B}$, samples containing red bar). The Spearman coefficient of correlation between biological runs was high, supporting the reproducibility of the results (Figure $3 \mathrm{C}$ and $3 \mathrm{D}$ and Additional File 2). Previously published technical replicate correlation coefficients range between 0.92 and 0.96 [51-53], centered in the range that we observed between 


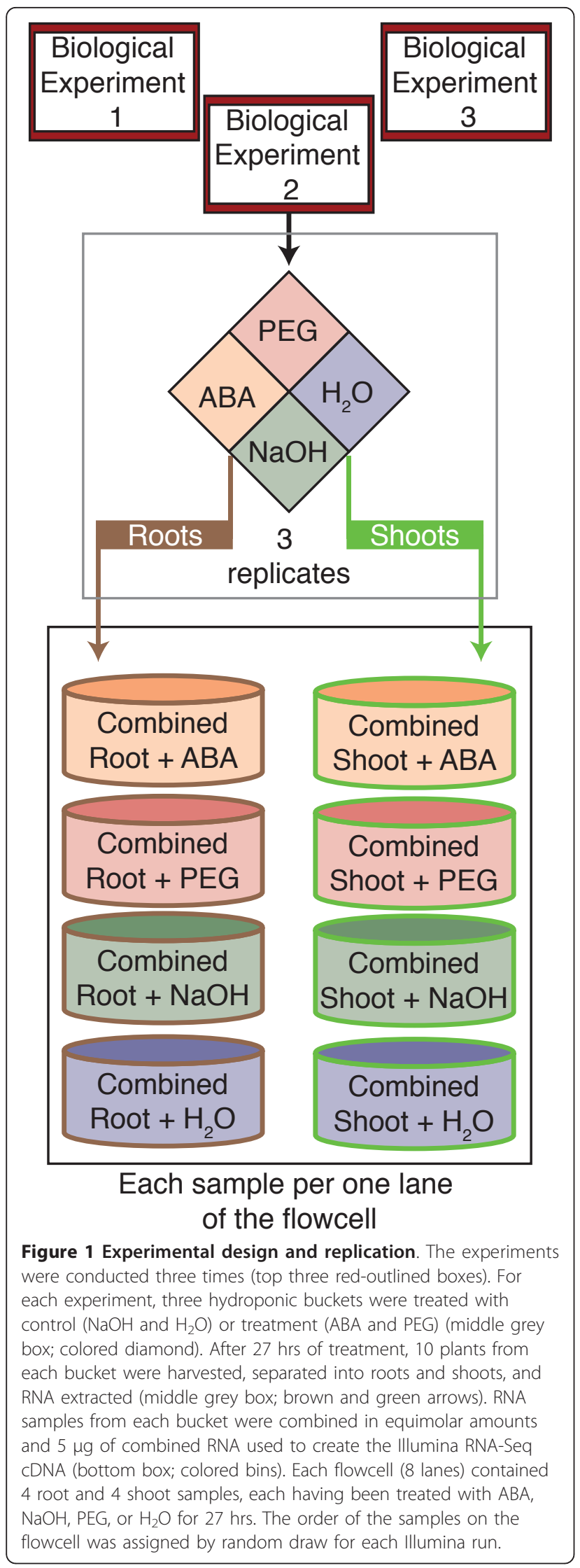

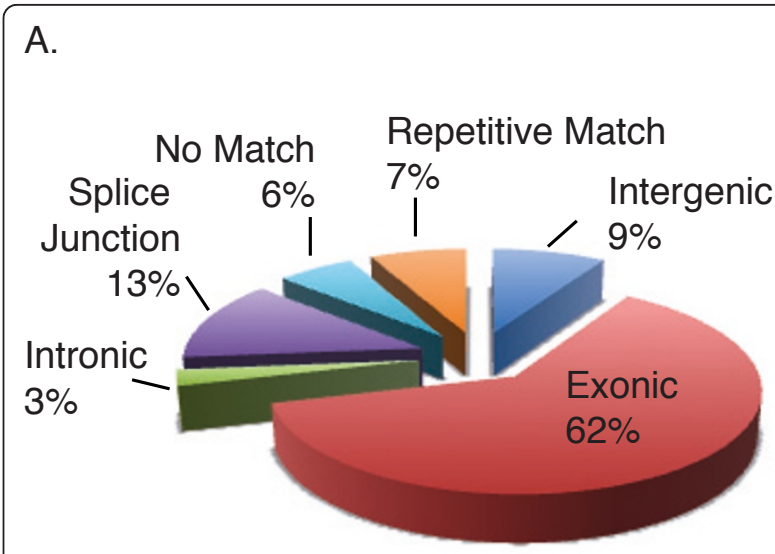

$535.9 \mathrm{M}$ reads

B.

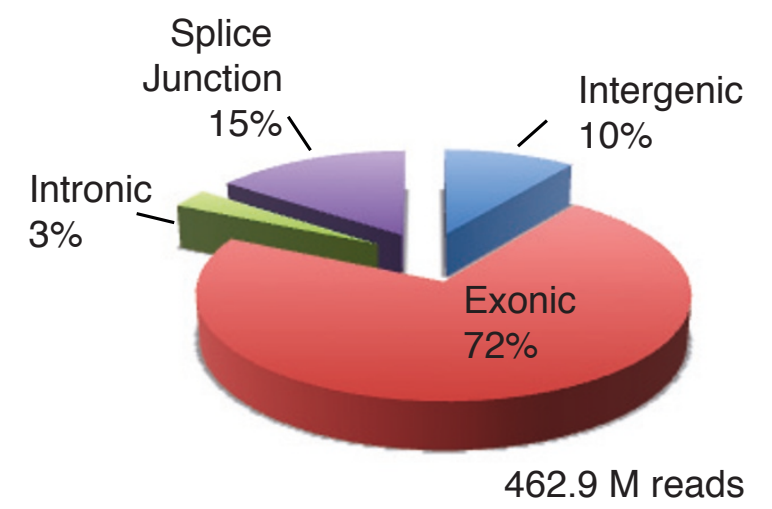

Figure 2 RNA-Seq analysis of the Sorghum bicolor transcriptome. Distribution of the total number of all sequencing reads that passed Illumina's filtering among annotated features across the sorghum genome (A). Distribution of the total number of all sequencing reads that passed Illumina's filtering and aligned uniquely to the sorghum genome (B).

biological replicates (Spearman coefficient of correlation of 0.91 - 0.99; Additional File 2).

As reported by Paterson et al. [43], the annotation of the sorghum genome identified 34,496 gene models, with $\sim 27,640$ of these considered bona fide, or high confidence, protein-coding genes following homology-based and $a b$ initio gene prediction methods combined with EST support from various cereals. The remaining $\sim 6,850$ sorghum gene models predicted from the genome sequence are considered low confidence [43] due to a lack of any additional support. In the present study, we were able to resolve 34,144 of the 34,496 gene models as a result of the lack of strand-specific information in the RNA-Seq cDNA. Unless specifically stated, this group of genes is what we refer to as "all annotated genes". In previous studies examining the rice [45] and soybean [46] transcriptomes via RNA-Seq, transcriptionally active 
Table 1 Summary of the RNA-Seq Data Combined from Three Independent Biological Experiments

\begin{tabular}{|c|c|c|c|c|c|c|c|c|}
\hline & \multicolumn{2}{|c|}{$\mathrm{NaOH}$-treated } & \multicolumn{2}{|c|}{ ABA-treated } & \multicolumn{2}{|c|}{$\mathrm{H}_{2} \mathrm{O}$-treated } & \multicolumn{2}{|c|}{ PEG-treated } \\
\hline & Shoot & Root & Shoot & Root & Shoot & Root & Shoot & Root \\
\hline Total 50bp single end reads (M) & 87.9 & 90.2 & 80.5 & 84.2 & 88.7 & 88.8 & 87 & 82.2 \\
\hline Total reads passing Illumina's purity filtering (PF) (M) & 70.7 & 68 & 64.5 & 65.3 & 66.3 & 67.7 & 67.2 & 66.2 \\
\hline Total PF reads that were "repeat masked" (M) & 5.4 & 4.9 & 4.6 & 5.0 & 4.9 & 4.7 & 5.3 & 4.8 \\
\hline Total PF reads with no match to the $S b$ genome $(M)$ & 4.4 & 4.4 & 2.3 & 3.5 & 6.3 & 6.6 & 1.2 & 2.4 \\
\hline Total reads uniquely mapped to the $S b$ genome $(\mathrm{M})$ & 60.7 & 58.6 & 57.5 & 56.5 & 54.7 & 56.3 & 59.7 & 58.9 \\
\hline Total reads mapped to annotated genes $(\mathrm{M})$ & 55.59 & 51.78 & 52.31 & 50.32 & 49.59 & 49.74 & 53.89 & 52.38 \\
\hline
\end{tabular}

genes were defined as those genes with at least two uniquely mapped raw counts. When this same definition was applied in the present study, we found transcriptional activity for 28,335 unique genes when considering all samples in all runs; 25,568 high confidence and 2,649 low confidence protein-coding genes, as well as 118 noncoding pri-microRNAs [43] (see Additional File 1). Thus $\sim 92.5 \%$ of high confidence annotated genes and $\sim 83 \%$ of all annotated genes reported by Paterson et al. [43] showed transcriptional activity in the plant tissues and treatments examined herein. By comparison, deep sequencing resulted in verified expression of $79 \%$ and $74.2 \%$ of the annotated genes in the combined 4 maize leaf developmental zones [54] and 14 soybean tissues [46], respectively.

Of the 34,144 sorghum gene models, 5,809 ( 17\%) did not have any detectable transcriptional activity across all samples indicating that either these models are not expressed in any of the developmental stages/tissues examined in the present study or the models do not represent bona fide genes. Of these genes, 3,915 ( 67\%) are of low confidence, and 1,819 ( 31\%) are located in pericentromeric regions, suggesting they may be transcriptionally silent. Additional transcriptome profiling across different developmental stages/tissues (e.g., apical and vegetative meristems, developing inflorescence) and/ or different abiotic/biotic environmental variables will be required to further assess the transcriptional activity of these genes.

\section{Differential Gene Expression Determination and Validation}

To determine the appropriate read depth criteria for differential gene expression, we examined the data for trends (see Methods for further details), and a 2X median read depth cutoff in one of the two samples being compared (i.e., ABA-treated vs. $\mathrm{NaOH}$-treated) was chosen for examination of differential gene expression. This cutoff value minimizes the rate of false positives while retaining genes of lower expression. In addition, only genes having a $\log _{2}$-fold change $\geq 1.0$ or $\leq-1.0$ and an adjusted $\mathrm{p}$-value $<0.05$, as determined by edgeR, were included in our analysis of differential gene expression.
These restrictions yielded differentially expressed (DE) gene lists ranging from $\sim 1,000$ to nearly 3,200 genes, depending on the tissue/treatment combination (Additional File 3). Among all tissues and treatments examined, 5,156 unique genes were classified as DE (Additional File 4); including 5,018 high confidence and 123 low confidence protein-coding genes, and 15 models annotated as pri-microRNAs [43]. Approximately a third of the DE gene products $(1,939$ out of 5,156$)$ are currently annotated as either predicted protein, similar to expressed protein or putative uncharacterized protein (Additional File 4) [43], which reflects the need for further proteomics studies in sorghum.

To validate the differential expression data, we performed quantitative reverse transcription PCR (qPCR) on randomly chosen mRNAs that were differentially expressed in response to ABA or osmotic stress. We conducted a total of 268 qPCR tests on a set of $157 \mathrm{DE}$ genes (Additional File 5). Overall, we found a strong correlation (86.6\%) to the RNA-Seq data (Additional File 5); all but one of the qPCRs that failed to correlate did so because no difference was seen between the treatment and control samples. When the qPCR and RNASeq results differed, they often did so for more than one control-treatment pair, suggesting that the location or design of these primers may not accurately reflect mRNA accumulation, possibly due to variations in splicing.

\section{Transcript Analysis in Response to ABA and Osmotic Stress}

We explored the relative number of DE genes in roots and shoots in response to treatment with ABA or PEG (Figure 4). In general, fewer genes exhibited altered expression in response to osmotic stress than exogenous ABA treatment. Following the $27 \mathrm{hr}$ ABA treatment, $\sim 2,300$ genes showed more than a 2-fold increase in gene expression whereas osmotic stress resulted in $\sim 1,650$ up-regulated genes (Figure $4 \mathrm{~A}$ and 4C). Similarly, $\sim 2,600$ genes were down-regulated more than 2-fold in ABA-treated plants compared to $~ 700$ genes in osmotically-stressed plants (Figure 4B and 4D). This is not surprising based on the involvement of 
A

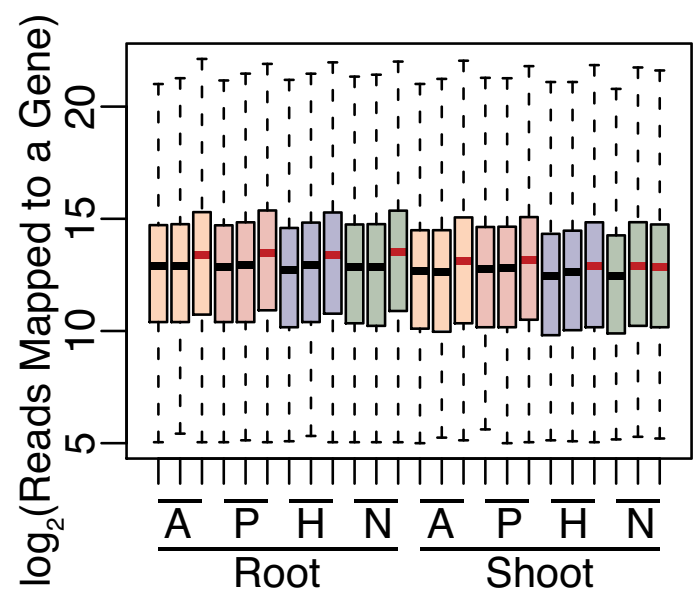

C

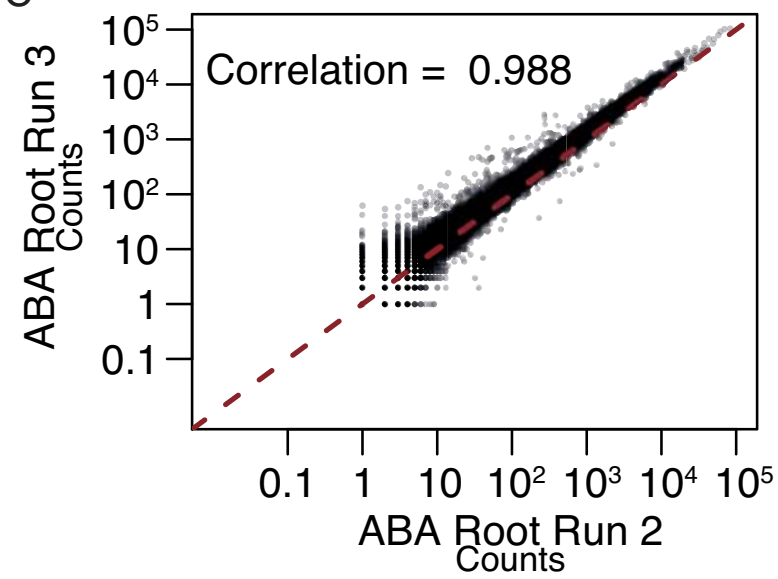

$\mathrm{B}$

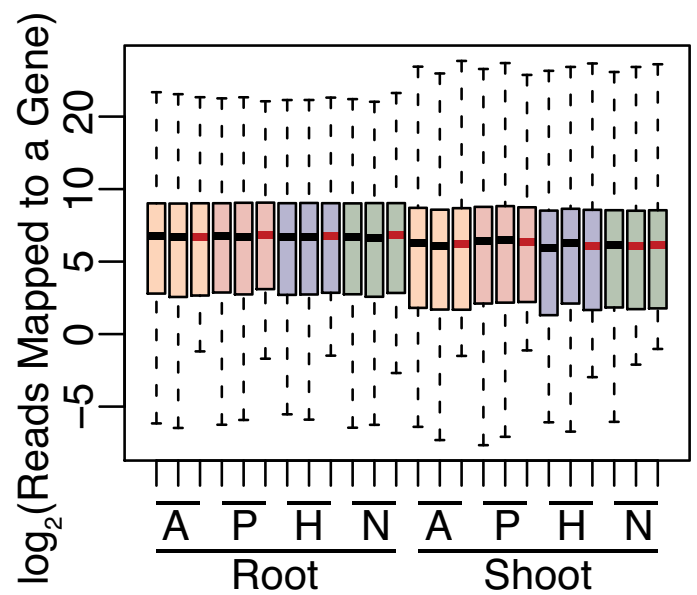

$\mathrm{D}$

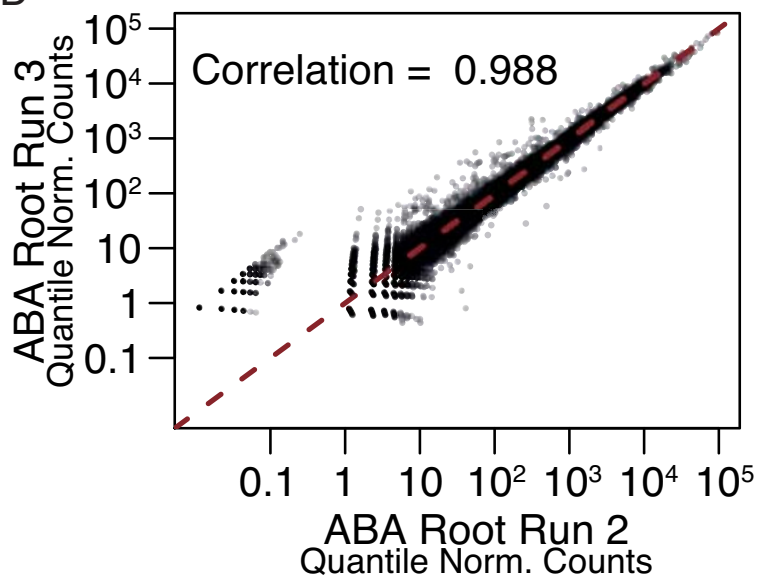

Figure 3 Quantile Normalization of RNA-Seq Reads. Box-and-whisker plots show median reads per gene (black and red bars) and varying ranges (colored boxes) for the lanes before normalization (A), which are removed after normalization (B). Red bars denote the lanes analyzed using updated RTA V1.6 software and therefore display an increase in total read counts per lane. Whiskers denote the lowest datum still within 1.5 interquartile range (IQR) of the lower quartile, and the highest datum still within 1.5 IQR of the upper quartile. Scatterplots of counts/gene between runs 2 and 3 in ABA-treated roots before $(C)$ and after quantile normalization (D). $A=A B A$-treatment; $P=P E G$-treatment; $H=H_{2} O$ control; $\mathrm{N}=\mathrm{NaOH}$ control.

ABA in response to plant stress, and its central role in other pathways, including dormancy in leaf [55-57], bud [55,58-65] and seed (reviewed in [66-68]). When comparing the overlap in DE genes between ABA and osmotic stress treatment, between $12-30 \%$ of the DE genes were in common between the two treatments depending on the tissue and whether gene expression was up- or down-regulated (Figure 4 and Additional File 3). When we consider the top five up- and downregulated genes in response to $\mathrm{ABA}, \mathrm{PEG}$, or responding to both $A B A$ and PEG treatment (Figure 4), we note that 29 out of 60 genes are considered to be uncharacterized or putative. As expected, genes similar to a late embryogenesis abundant (LEA) protein and a WSI18 protein, both of which are induced by water stress, and a dehydrin were in the top five genes upregulated in response to both PEG- and ABA-treatment in roots and shoots, respectively. LEA proteins are hydrophilic proteins induced by drought stress and ABA, a subclass of which includes dehydrins (reviewed in [69-71]). Although their function is unknown, it has been suggested that LEAs act as water-binding molecules, membrane-stabilizers, and ion modulators (reviewed in [69-71]). A gene similar to OSIG$\mathrm{Ba} 010 \mathrm{~B} 08.10$, whose gene product contains sugar substrate transporter domains was down-regulated in response to both ABA and PEG in roots, and a gene similar to peroxidase 6 was down-regulated in response to both treatments in shoots. Peroxidases comprise a large family of enzymes that function as antioxidants; 


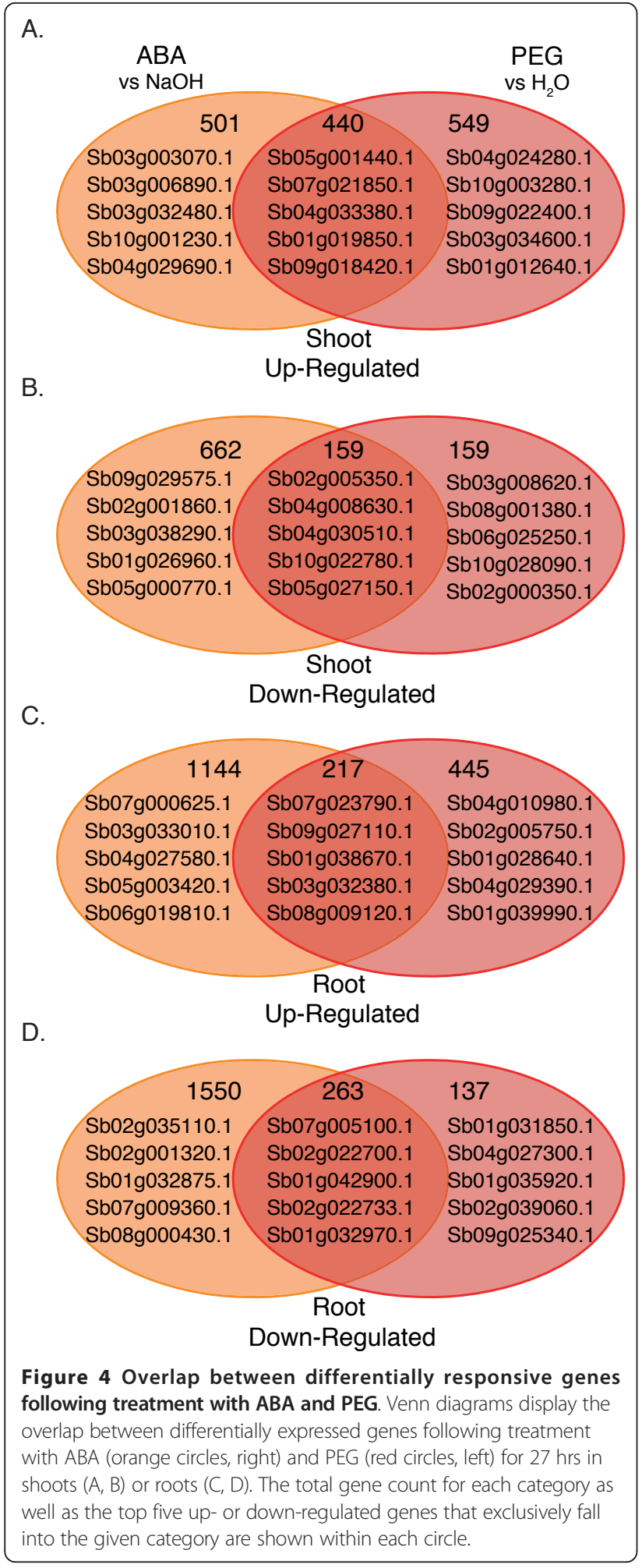

as such, different peroxidases respond in various ways to drought stress [72], suggesting some family members, including Sb04g008630, may be down-regulated under water stress whereas others increase.
To further explore the genes responding to exogenous $\mathrm{ABA}$ and osmotic stress treatment (and their functions within the plant), gene ontology (GO) [73] and pathway enrichment analysis were performed. Enrichment analysis allows exploration of large datasets by suggesting that more genes fall within certain categories/pathways/ groups than would be expected by a random draw. In total, 191 GO categories and 72 SorghumCyc pathways exhibited enrichment for DE genes based on significant p-values (GO analysis) or Z-scores plus p-values (pathway analysis) depending on the tissue/treatment combination being examined (Additional Files 6 and 7). Examples of GO categories exhibiting enrichment in DE genes included those involved in biotic and abiotic stress, cell growth and development, hormone biosynthesis, and sugar biosynthesis (Additional File 6). Similar to the GO analysis, numerous SorghumCyc hormone biosynthetic pathways showed enrichment in DE genes as did pathways involved in the biosynthesis of osmoprotectants, sugars, and amino acids, to name a few (Additional File 7).

While it is beyond the scope of this paper to discuss each GO category and metabolic pathway exhibiting DE gene enrichment, several examples of tissue- and/or treatment-specific enrichment are discussed in more detail below with particular emphasis on the role of $\mathrm{DE}$ genes in stress and defense response as well as possible influences on development. For those investigators desiring a broader overview of enriched GO categories and metabolic pathways, complete listings can be found in additional files 6 to 8 .

\section{ABA and Osmotic Stress Pathways in Roots and Shoots}

GO categories enriched for genes up-regulated in response to exogenous $\mathrm{ABA}$ or osmotic stress in roots and shoots include responses to light intensity, heat, wounding, and hydrogen peroxide (Additional File 6). Additionally, genes enriched in GO categories such as response to stress, cold, and water deprivation were also up-regulated in ABA and osmotic stressed roots and shoots, although in some treatment/tissue combinations, certain genes from these categories were down-regulated as well. ABA has been shown to play a role in the stress responses listed in these GO categories (reviewed in [35,38,74-76]), thereby supporting our results.

An example of a differentially expressed metabolic pathway common to both ABA treatment and osmotic stress includes the choline biosynthetic pathway, which was enriched for $\mathrm{DE}$ genes in roots and shoots based on GO and Z-score analysis (Additional Files 6 and 7). Choline can be oxidized to glycine betaine, a strong osmoprotectant $[77,78]$. In contrast to the choline biosynthetic pathway, we did not observe enrichment for the glycine betaine biosynthesis pathway based on the 
Z-score pathway analysis. This may be due to the fact that SorghumCyc pathways are computationally generated and populated by orthologous gene annotation (http://www.gramene.org/pathway/sorghumcyc.html).

As an alternate method to explore the influence of DE genes on pathway function, we analyzed the ratio of reactions in a given pathway that contain DE genes over all reactions within that pathway (Additional File 8). We note that out of the two reactions annotated in the glycine betaine pathway, at least one contained DE genes (data not shown). The altered regulation of the glycine betaine biosynthesis pathway is therefore still possible if a rate-limiting step is differentially expressed. A related osmoprotectant pathway, ß-alanine betaine biosynthesis, contained DE genes in all three reactions in the 4 tissue/ treatment samples examined (Additional File 8). In support of this analysis method, the $B$-alanine betaine expressing members of the Plumbaginaceae family have adapted to a wide variety of environments, including salt marshes and water-deficient locations, whereas glycine betaine producing members of the family have not [79].

Differential expression in amino acid metabolism pathways in response to osmotic stress and exogenous ABA was also indicated by analysis of SorghumCyc annotated pathways. The proline biosynthesis pathways contained DE genes in two out of three reactions assigned to the pathways for roots and shoots (Additional File 8). Proline is a known osmoprotectant employed by plants to enhance tolerance to abiotic stress, including drought. Proline can function as a reactive oxygen species scavenger, protect and stabilize proteins, and enhance the functions of certain enzymes (reviewed in [80-82]). In addition to the proline biosynthesis pathways, the majority of the reactions within the valine and leucine degradation pathways contain DE genes in response to exogenous $\mathrm{ABA}$ and osmotic stress (Additional File 8). Valine [83-86] and leucine [84-86] have been shown to accumulate in plants undergoing water stress, and their biosynthesis is auto-regulated by branched chain amino acid transferases (BCATs) as these enzymes control both the last step in biosynthesis and the first step in degradation $([86,87]$ and reviewed in [88]). Although we did not find differential expression of the BCAT homologs, it has been suggested that $\mathrm{BCAT}$ expression requires both dehydration and endogenous $\mathrm{ABA}$, as exogenous application of $\mathrm{ABA}$ alone did not increase expression [84]. Although valine and leucine levels increase in Arabidopsis [84,86], tomato [85] and Bermuda grass [83], their turn-over rates have not been investigated. As the effect of the differential gene regulation on the accumulation of the products of the pathways, valine and leucine, is unknown, we suggest that the pathways are differentially regulated following $\mathrm{ABA}$ or osmotic stress treatment of sorghum tissues.
Several hormone biosynthetic pathways were also affected by exogenous ABA and osmotic stress in shoot and root tissue. Pathways for ethylene biosynthesis from methionine, gibberellin, JA, and brassinosteroid contain $\mathrm{DE}$ genes in $60 \%$ or more of their reactions (Additional File 8); some of these pathways also show enrichment based on Z-score pathway (Additional File 7) and GO analysis (Additional File 6), although not in every tissue/ treatment combination. A relationship between water stress and ABA and GA has been reported in maize [34], soybean [33], and Arabidopsis [32,89]. Seo et al. [89] detail evidence, including increased expression of GA biosynthesis genes in the aba2-2 mutant, that supports possible regulation of GA metabolism by ABA, which is consistent with the differential expression of gibberellin biosynthesis genes in sorghum subjected to exogenous ABA and osmotic stress treatment.

Cytokinin degradation and conjugating pathways contain DE genes in every reaction within the pathway in all tissue/treatment samples (Additional File 8), although only roots treated with ABA or osmotic stress displayed enrichment for cytokinin conjugating pathways, and osmotically stressed shoots exhibited enrichment for cytokinin degradation by Z-score analysis (Additional File 7). Several types of cytokinin conjugations, including the creation of cytokinin glucosides, can render cytokinins biologically inactive. Studies conducted in tobacco have demonstrated that while the total amount of cytokinin rose under drought stress or ABA treatment, the majority of the cytokinin pool found within the roots was in the inactive form [90,91], suggesting an inverse relationship between ABA (drought) stress and active cytokinin accumulation. The present results support this hypothesis. Arabidopsis and tobacco plants over-expressing cytokinin-degrading cytokinin oxidase/dehydrogenase genes display increased root biomass as well as increased survival rates after water deprivation [92], reinforcing the link between decreased cytokinin levels and drought tolerance.

Cross-talk between hormone pathways via associated genes is becoming a common realization in plants, especially in leaf tissue $([32,34,89]$ and reviewed in $[93,94])$. Considering a network based on SorghumCyc hormone pathways and their neighbor pathways (pathways that contain overlapping DE genes with those found in the hormone-related pathways) (Figures 5 and 6), we observe that few of the hormone pathways share overlapping DE genes. Only the brassinosteroid and JA biosynthesis pathways, and cytokinin glucoside and IAA conjugate biosynthesis pathways are directly connected via DE genes (Figures 5 and 6, squares labeled $A$ and I, and $\mathrm{C}$ and $\mathrm{H}$, respectively). The lack of overlapping $\mathrm{DE}$ genes within the hormone pathways suggests that if hormone levels are changing as a result of alterations at the 
A.

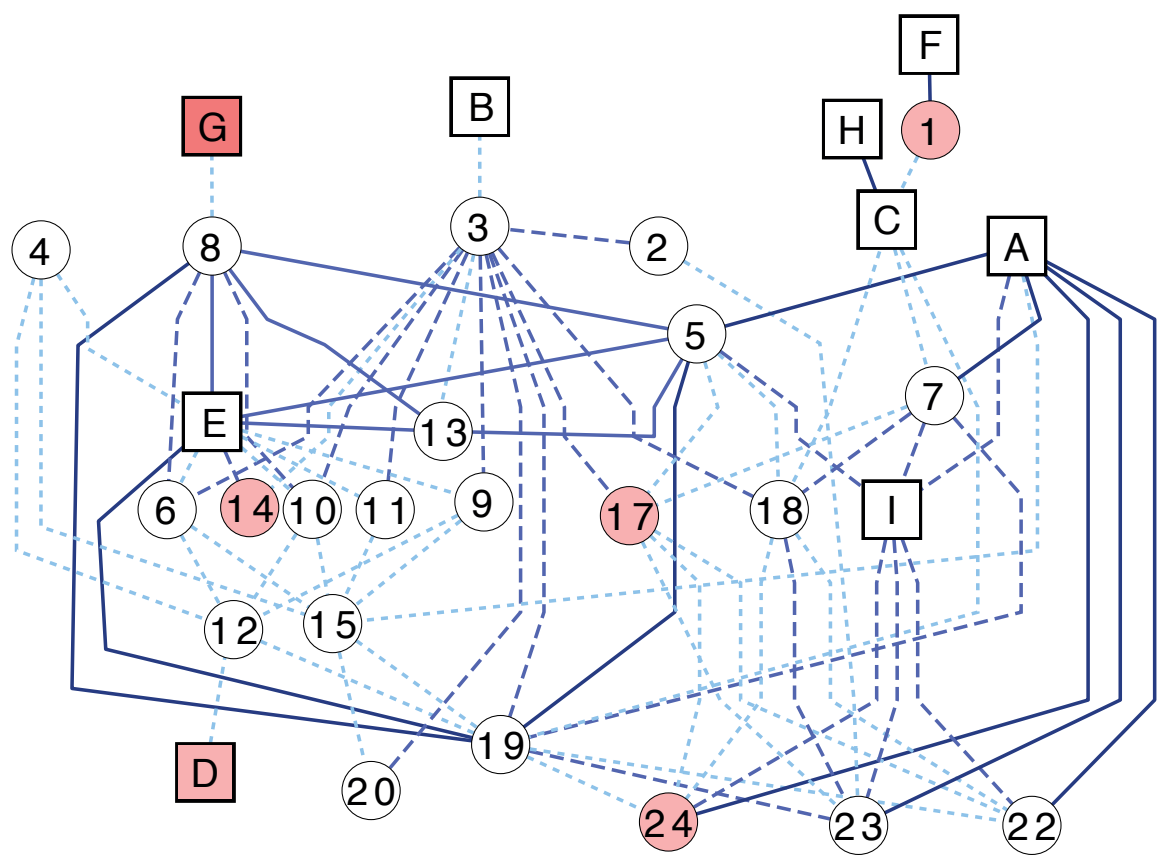

B.

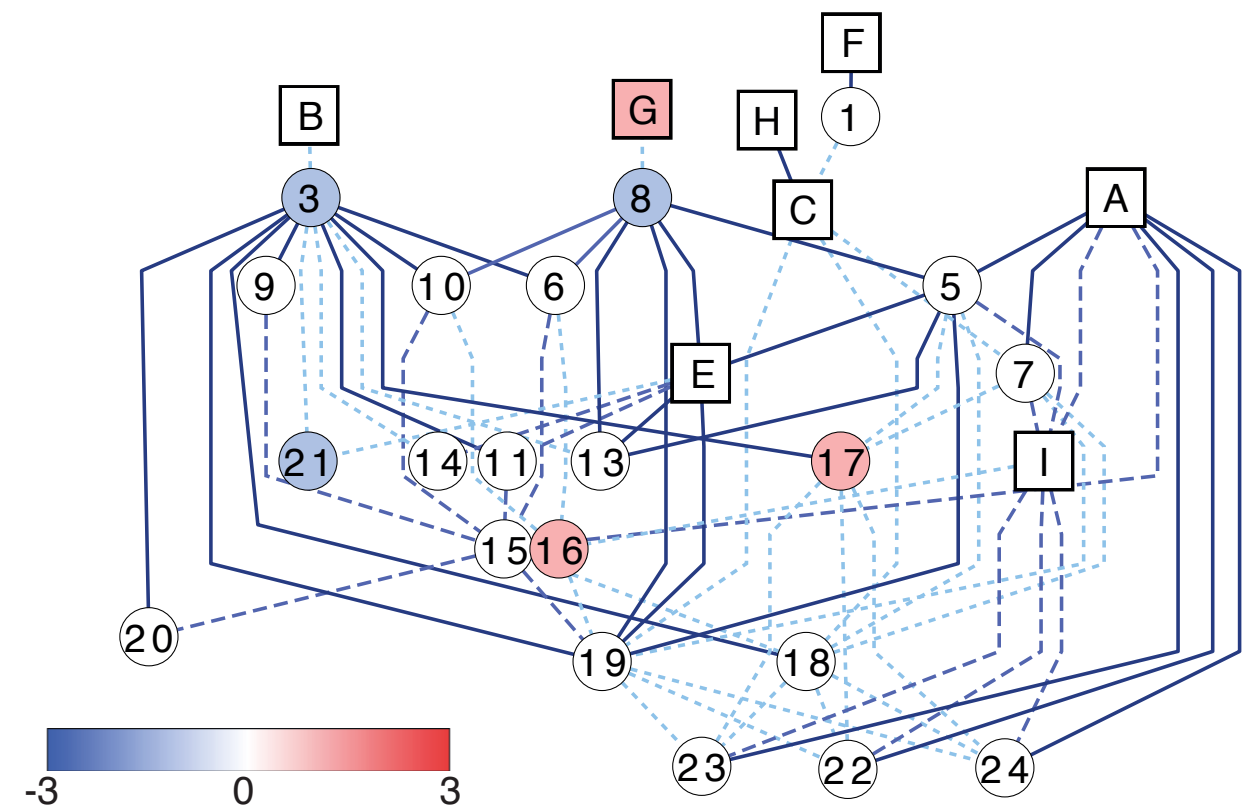

Figure 5 Networks of hormone pathways in ABA-treated plants. Networks were created considering the shortest paths connecting each hormone-related pathway to another hormone-related pathway in shoots (A) and roots (B). Hormone-related and non-hormone-related pathways are denoted as squares and circles, respectively, and are shaded based on the number of genes up-regulated within the pathway minus the number of genes down-regulated. Pathways that contain equal numbers of up- and down-regulated genes are white. Edges connecting the pathways occur only when differentially expressed genes are in common between the two pathways. Dark blue solid lines, blue long-dashed lines, and light blue short-dashed lines denote $\geq 10,6-9, \leq 5 \mathrm{DE}$ genes, respectively, in common between the pathways. Pathway names are as follows: $A$, brassinosteroid biosynthesis; $B$, cytokinins degradation; $C$, cytokinins glucoside biosynthesis; $D$, ent-kaurene biosynthesis; E, ethylene biosynthesis from methionine; F, gibberellin biosynthesis; G, gibberellin inactivation; H, IAA conjugate biosynthesis; I, jasmonic acid 
biosynthesis; 1, anthocyanin biosynthesis; 2, ascorbate biosynthesis; 3, betanidin degradation; 4, Calvin cycle; 5, dTDP-L-rhamnose biosynthesis; 6 fructose degradation to pyruvate and lactate; 7 , galactose degradation; 8, $\gamma$-glutamyl cycle; 9, gluconeogenesis; 10, glycolysis; 11 , methionine biosynthesis; 12, oleoresin sesquiterpene volatiles biosynthesis; 13, oxidative ethanol degradation; 14, phenylalanine biosynthesis; 15 , phenylpropanoid biosynthesis; 16, ribose degradation; 17, starch biosynthesis; 18, sucrose degradation; 19, sucrose degradation to ethanol and lactate; 20, threonine biosynthesis from homoserine; 21, triacylglycerol degradation; 22, UDP-galactose biosynthesis; 23, UDP-glucose conversion; 24, UDP-N-acetylgalactosamine biosynthesis.

transcriptional level, they do so in a non-concordinate manner. Taken together, our data support indirect 'cross-talk' between the various hormones in response to osmotic stress and ABA. As many of the pathways contain both up- and down-regulated genes often in equal number (Figures 5 and 6; white circles and squares), the effect of differential gene expression on the pathway outputs cannot be predicted from the present results.

\section{Defense Pathways are Regulated by ABA and Osmotic Stress in Shoots}

The 13-lipoxygenase (13-LOX) and 13-HPL pathways as well as the divinyl ether biosynthesis II pathway were enriched in DE genes in shoots following treatment with either ABA or osmotic stress (Additional File 7). In plants, the most common LOX substrates, linoleic and linolenic acids, are converted into a variety of bioactive mediators involved in plant defense, senescence, seed germination, and plant growth/development $([95,96]$ and reviewed in [97-99]). ABA is also found to increase 13-LOX genes in maize leaves [100], supporting a common role for the 13-LOX pathways in ABA and osmotic stress response in maize and sorghum. Two 13-LOX genes in maize have been characterized and display distinct transcriptional patterning in response to ABA as exhibited by differing peak response times, as well as induction of only one of the genes in response to cold, a stress response in which ABA plays a role [100]. GO analysis revealed enrichment for DE genes in defense response, and abiotic stresses including heat, osmotic, and reactive oxygen species (Additional File 6) for both 27 hr ABA- and osmotic stress-treated shoots. In Arabidopsis [101], a shift towards a general abiotic stress response was also observed $6+$ hrs after stress induction in shoot tissues similar to what we observe in sorghum.

\section{ABA and Osmotic Stress Treatments Mimic Root Disease Response}

Examination of GO categories displaying DE genes in roots in response to $\mathrm{ABA}$ or osmotic stress revealed a series of pathways that have been implicated in a plant's response to pathogen attack [102-107]. GO categories enriched in up-regulated DE genes in osmotically stressed roots and down-regulated in ABA-treated roots included cell wall modification and cell growth, response to nitrate, JA stimulus, SA stimulus, and hypersensitive response. By comparison, the GO category hydrogen peroxide catabolism was enriched for genes down-regulated in osmotically stressed and ABA-treated roots (Additional File 6). Cell wall modification and oxidative stress response has been suggested to be regulated by JA [106], and JA treatment has been shown to decrease the transcriptional activity of genes which respond to ABA leading to an antagonistic relationship between the two hormones [106]. Salicylic acid and ABA have antagonistic roles in plant defense $([104,105]$ and reviewed in [107]); SA is induced in plants under pathogen attack, and the ABA biosynthetic pathway is induced in the plant by the pathogen to reduce plant response (reviewed in [107]). Salicylic acid and JA enhance biotrophic and necrotrophic resistance, respectively, with possible cross-talk between the two hormones (reviewed in [102,107]). Salicylic acid, JA, and ABA are complexly related in pathogen response, which is normally accompanied by an oxidative burst of reactive oxygen species (ROS) (reviewed in [102,103]). Peroxides are considered to be pathogen responsive and remove hydrogen peroxide from the cell (reviewed in [103]). Intriguingly, they also increase cell wall rigidity by cross-linking cell wall components (reviewed in [103]). It remains to be determined whether the GO categories highlighted in this cascade of events are solely due to a side effect of altered hormone levels due to osmotic stress or are part of a survival mechanism activated in water-limited conditions.

\section{Remodeling and Growth in PEG-Treated Roots}

A number of GO categories involved in growth and remodeling exhibited specific enrichment in roots following osmotic stress treatment. For example, up-regulated genes in PEG-treated roots were enriched in the GO categories for nodulation and regulation of epithelial cell differentiation, whereas down-regulated genes were enriched in the GO categories of lateral root development and nitrate transport (Additional File 6). These results support a well-established role for root remodeling in response to osmotic stress [108-110]. Genes down-regulated in response to osmotic stress display enrichment for auxin efflux, phosphate transport, and lateral root development (Additional File 6). Low phosphate increases lateral root development and reduces 
A.

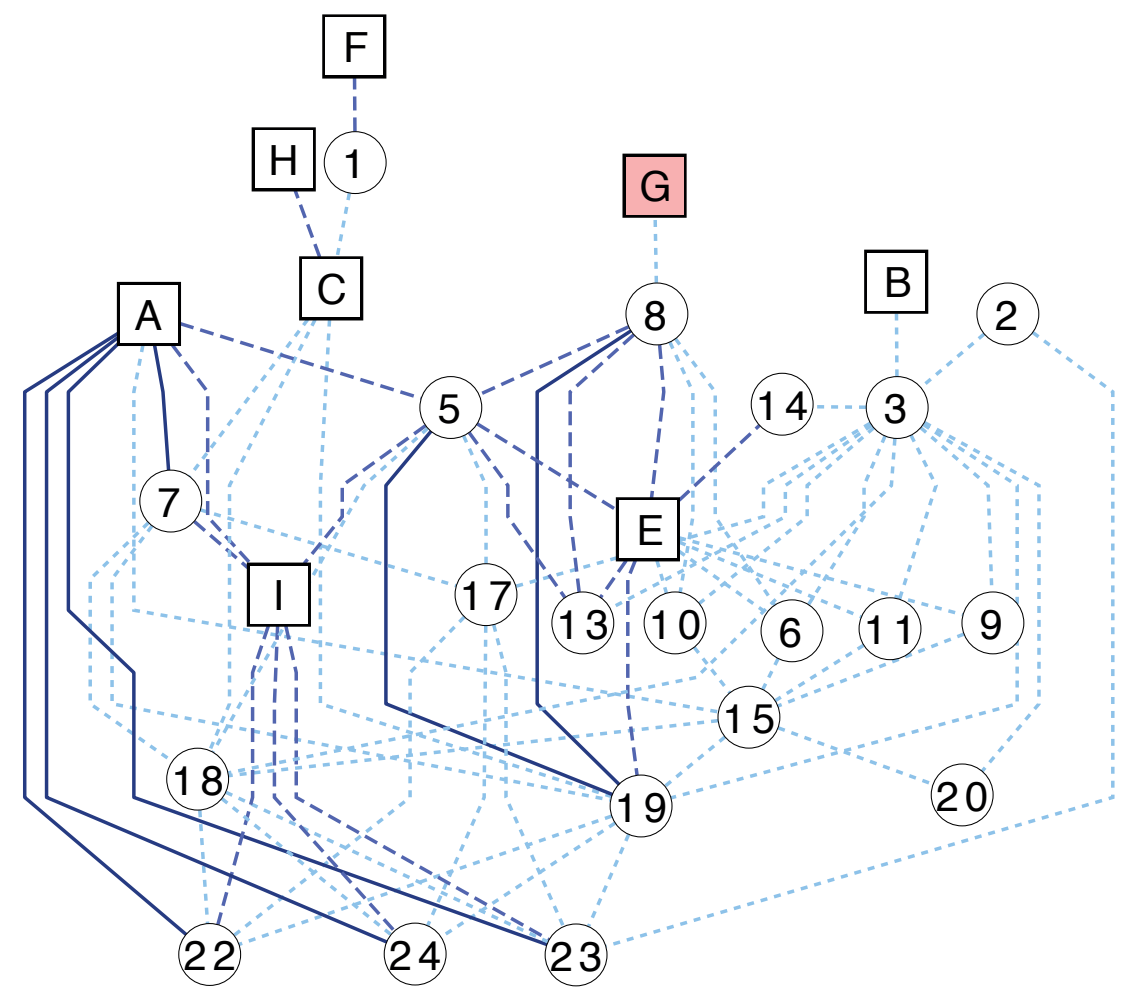

B.

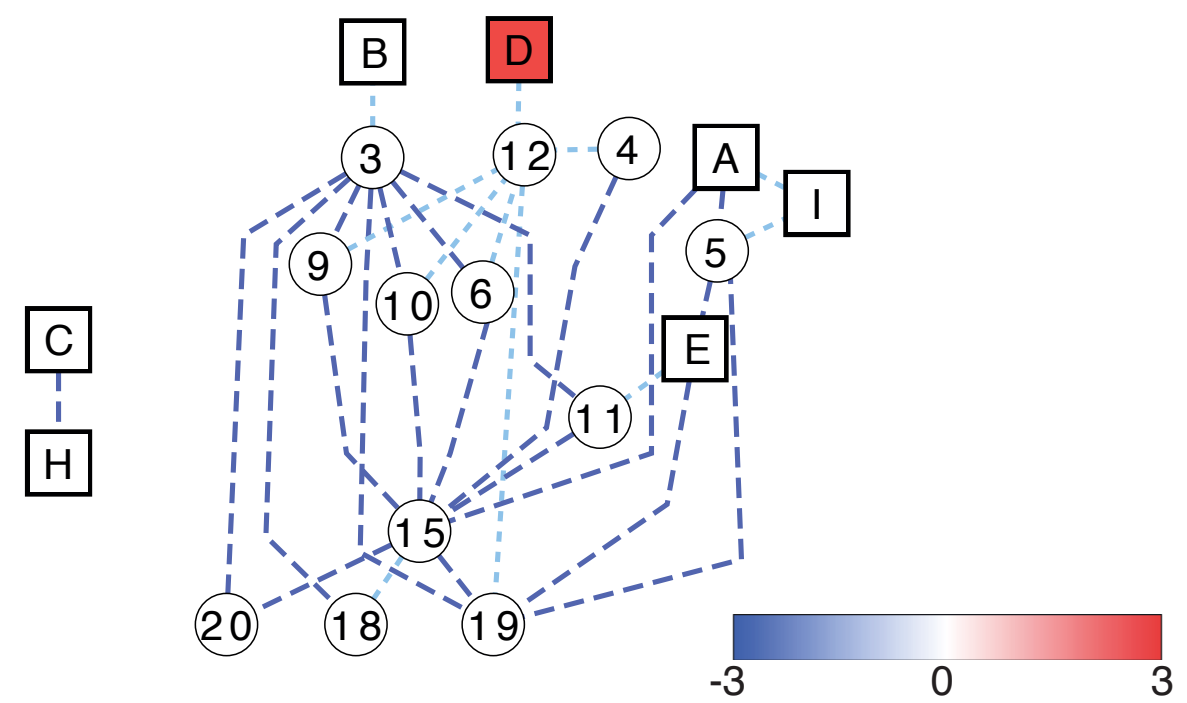

Figure 6 Networks of hormone pathways in PEG-treated plants. Networks were created considering the shortest paths connecting each hormone-related pathway to another hormone-related pathway in shoots (A) and roots (B). Hormone-related and non-hormone-related pathways are denoted as squares and circles, respectively, and are shaded based on the number of genes up-regulated within the pathway minus the number of genes down-regulated. Pathways that contain equal numbers of up- and down-regulated genes are white. Edges connecting the pathways occur only when differentially expressed genes are in common between the two pathways. Dark blue solid lines, blue long-dashed lines, and light blue short-dashed lines denote $\geq 10,6-9, \leq 5 \mathrm{DE}$ genes, respectively, in common between the pathways. Pathway names (A-I and 1-24) are denoted as in Figure 5. 
primary root elongation through altered auxin distribution [111-116], suggesting an alteration in root architecture in osmotic-stressed roots. Enhanced root growth and drought tolerance were associated with reduced cytokinin levels in Arabidopsis and tobacco [92], and we observed enrichment for cytokinin glucoside biosynthesis in roots treated with PEG (Z-score > 3; Additional File 7), suggesting that osmotic stress may play a role in root remodeling and growth in sorghum.

\section{Transcriptional Regulation of Differentially Expressed Genes}

ABA-responsive elements (ABREs) [117], dehydrationresponsive elements (DREs) [118], and low-temperatureresponsive elements (LTRE) [119,120] are known to regulate gene expression in response to ABA, drought, and cold stress, respectively. Given that genes in our DE lists were alternatively expressed due to the presence of ABA or osmotic stress, we searched $1000 \mathrm{bp}$ upstream of all sorghum genes for the presence of cis-acting elements found within PlantCARE (http://bioinformatics.psb. ugent.be/webtools/plantcare/html/) [121,122] and PLACE (http://www.dna.affrc.go.jp/PLACE/index.html) $[123,124]$, and highlighted those elements that are known to be involved in ABA and drought response and those that support the models of gene interaction supported by our GO and SorghumCyc analysis.

Transcription factor analysis revealed that the AP2EREBP TF family is over-represented in DE genes from shoots following ABA treatment ( $\mathrm{p}$-value $<0.02$ ). The AP2-EREBP TF family consists of several subgroups including dehydration-responsive element binding proteins (DREBs), ethylene response factors (ERFs), APETELA2 (AP2)-related proteins, as well as those related to ABI3/VP1 (RAVs), which contain both AP2 and B3 motifs (reviewed in [125]). Genes up-regulated in shoots following ABA-treatment are also enriched for cis-elements including the dehydration-responsive elements DRE2COREZMRAB17 and DRECRTCOREAT, as well as RAV1BAT, a binding site for RAV1, a member of the AP2-EREPB TF (Additional File 9). AP2-EREBP TF family members play roles in response to both hormones (ABA) and drought stress (reviewed in [125]), and our cis-element enrichment analysis supports similar claims in sorghum.

Sugar-repressive motifs were enriched in genes downregulated in shoots by $\mathrm{ABA}$ and osmotic stress (Additional File 9). Sugar production increases in Arabidopsis, rice and other plants exposed to osmotic stress (reviewed in [74,126-130]), and enrichment of sugarrepressive motifs in genes down-regulated by osmotic stress is consistent with this observation.

Although several of the same cis-elements are enriched across all samples, few transcription factors are highly expressed in common between roots and shoots after exogenous ABA- and osmotic stress treatment. A small set of 6 TFs are up-regulated in all tissue/treatment combinations that include bZIP - Sb04g034190; C3H - Sb09g006050, Sb03g003110; HSF - Sb03g033750, Sb10g021800; and MYB-related - Sb03g003100 (Additional File 3). ABF2 (AREB2), the Arabidopsis homolog of Sb04g034190 (Additional File 3), is up-regulated in response to drought [131] and ABA-treatment and plays a role in glucose response as well as salt, heat, and oxidative stress tolerance [132]. AtOZF1 (At2g19810) is the homolog to both Sb09g006050 and Sb03g003110 (Additional File 3) and AtOZF1 mRNA accumulation is enhanced when seedlings are exposed to ABA, salt, and hydrogen peroxide [133]. AtOZF1 has recently been shown to localize in or attach to the plasma membrane and improve oxidative stress resistance by enhancing the transcription of cytosolic ASCORBATE PEROXIDASE 1 (APX1) and GLUTATHIONE S-TRANSFERASE TAU 5 (AtGSTU5), two antioxidant enzymes [133]. The functions of homologs to Sb03g033750, Sb10g021800, and Sb03g003100 have not been investigated.

Combining information from PlnTFDB [134,135], PlantTFDB [136-138], and GrassTFDB [139], sorghum contains 79 TF families and 2202 unique genes, 95 of which are assigned to more than one TF family. In examining specific tissue/treatment combinations, ABAtreated roots displayed the greatest change in TFs with expression of 101 up-regulated and 112 down-regulated genes (Additional File 3). Approximately 50\% of the differentially expressed TFs, whether up- or down-regulated, were specific for a given tissue/treatment combination (Additional File 3). The AP2-ERF family of TFs is the most altered in expression when sorghum seedlings are exposed to ABA or osmotic stress (data not shown). This family of TFs has been shown to respond to a diverse array of biotic and abiotic stresses in rice [140]. Furthermore, the overexpression of members of this TF family in rice [141], Trifolium alexandrinum L. [142], and tobacco [143] resulted in an increased tolerance to salt and drought in transgenic plants.

\section{Gene Products of Unknown Function across Plant Species} are Differentially Expressed in Response to Abiotic Stress Given the advances in genomic technology platforms, the unique ability to compare transcriptomes across several species can be exploited to cross-reference information concerning genes and gene function. Lists of alternatively expressed genes in rice [24,26,144,145], maize [30], and Arabidopsis [13,15,17] under various forms of drought stress have been published. Many of these DE genes were of unknown function. We hypothesize that orthologs exist between genes of unknown 
function across species, and that a subset of these orthologs will be differentially expressed in response to abiotic stress. We compared orthologs of sorghum, rice, maize, and Arabidopsis (http://www.gramene.org) [146], cross-referenced published drought-responsive speciesspecific gene lists $[13,17,26,30,144,145]$, and identified genes of unknown function (Figure 7A). We were interested in genes of unknown function that respond differentially under osmotic stress and therefore did not filter our results based on directionality of the gene expression in response to drought as the published gene lists were created under various severities of drought [30], using different technologies [13,17,26,30,144,145], and the species considered respond differently to water-limited conditions. When sorghum DE gene lists were compared with the sorghum orthologs of published drought responsive gene lists from rice, maize, and Arabidopsis, we discovered 51, 82, and 183 genes, respectively, of unknown function that were drought responsive (Figure 7B and Additional File 10). Two sorghum genes, Sb01g045990 and Sb03g005990, and their orthologs were differentially expressed in all four species (Figure 7B and Additional File 10).

To investigate these DE genes further, we searched for stress-responsive cis-acting promoter elements by scanning 1000bp upstream of orthologous genes. The 51 sorghum genes orthologous to unknown rice genes responsive to drought were enriched for ABREs and CGTCA-motifs; motifs that are involved in responses to ABA [147] and methyl jasmonate [148], respectively (Additional File 11). The promoters from the rice orthologs show enrichment for both SORLIP1AT and ABRE motifs (Additional File 12). The 183 drought-responsive sorghum genes with drought-responsive orthologs of unknown function in Arabidopsis are enriched for Box $S$, involved in the wounding and pathogen response [149], CCAAT-box motifs, possible binding sites for MYB proteins [150], and ABREs (Additional File 11). The promoters for the Arabidopsis orthologs are enriched for a circadian clock motif, which is involved in circadian mRNA accumulation [151] (Additional File 12). The 82 sorghum genes with orthologs in maize with unknown function and responsiveness to drought are enriched in ABREs, Box S, DRECRTCOREAT, a dehydration responsive element [152,153], as well as, CBFHV and LTRECOREATCOR15 [119,120], which are both involved in low temperature response (Additional File 11). The corresponding maize ortholog promoters are enriched for the TGA-1 motif, a known auxinresponsive element [154,155] (Additional File 12). Due to the conservation of these presently unknown gene products, our results suggest that these elements play an important and ecologically conserved role in the response to water-limiting environments.

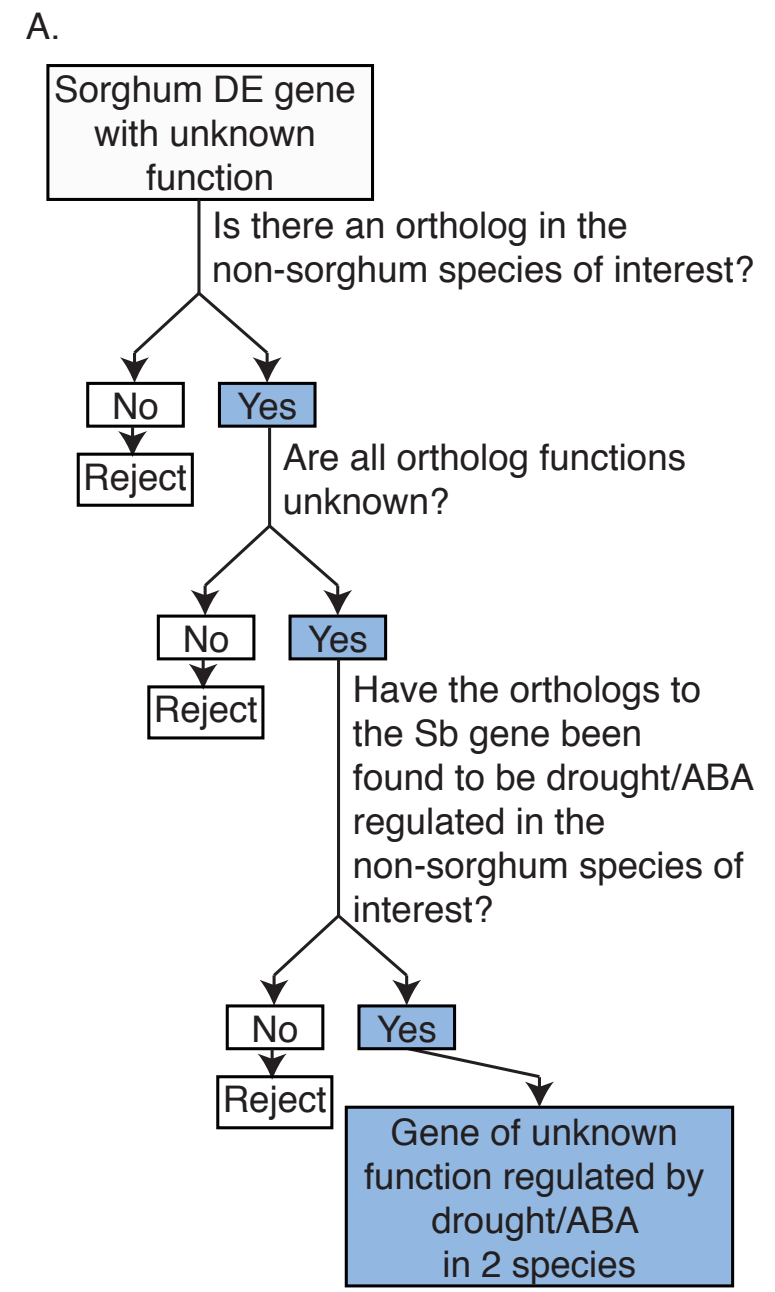

B.

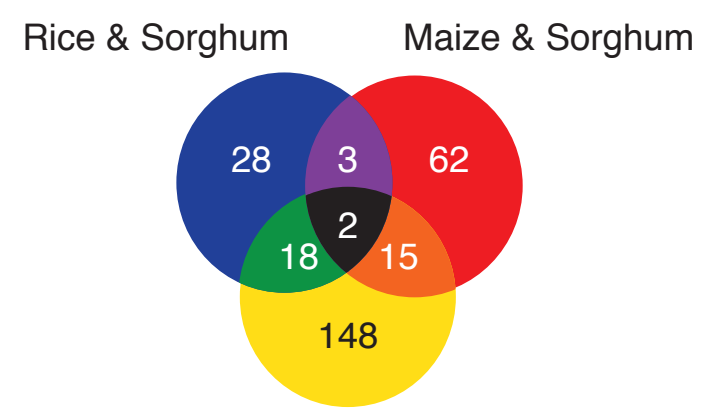

Arabidopsis \& Sorghum

Figure 7 Determining the genes of unknown function that respond to drought or ABA treatment across species. Decision tree used to determine which genes and their orthologs were regulated by drought/ABA across different species (A). For each sorghum gene, the tree was traversed 3 times; once for each nonsorghum species: rice, maize, Arabidopsis. Venn diagram displaying the overlap of drought-responsive sorghum genes of unknown function that had drought-responsive orthologs of unknown function in other species (B). Each gene is found in 2 or more species. 


\section{Conclusions}

The present study demonstrates the value of whole-genome transcriptome analysis generated by RNA-Seq for accurate quantification of gene expression on a genomewide scale. Through mapping more than 689.5 million sequence reads, we established transcriptome data sets for sorghum subjected to osmotic stress, exogenous $\mathrm{ABA}$, or control conditions. Moreover, mined in parallel with existing RNA-Seq resources from other species, this expression compendium provides a powerful resource for cross-species comparisons of gene expression and function. Thus, our initial analysis provides insight into how osmotic stress and hormonal treatment alter gene expression in this drought-tolerant cereal species, and has facilitated an initial assemblage of cis-regulatory elements and transcription factors working in union to alter gene expression in response to these conditions.

Concomitantly, we expanded on the previous sorghum cDNA-array differential gene expression study of Buchanan et al. [31] by examining the expression of all annotated protein and non-coding genes, while concomitantly refining the methodology used to quantify gene expression. Sequencing of the sorghum genome [43] and development of SorghumCyc allowed for exploration of differentially expressed pathways, and an initial glimpse into the intricate involvement of metabolic pathway cross-talk in the cellular response to abiotic stress. The sorghum RNA-Seq data set represents a communitywide resource that will allow scientists to query gene expression and annotation, and provides an initial look at the cascade of global gene expression patterns that occur in response to water-limiting environments.

\section{Methods}

\section{Plant Materials and Growth Conditions}

Seeds of Sorghum bicolor genotype BTx623 were germinated by soaking in distilled, aerated water overnight, and then transferred to moist germination paper for 3 days. The seedlings were then transferred to $0.5 \times$ Hoagland's solution and allowed to grow for an additional 5 days in a controlled environment chamber with a day length of $12 \mathrm{hrs}, 50 \%$ humidity, and day/night temperatures of $31^{\circ} \mathrm{C} / 22^{\circ} \mathrm{C}$, respectively. At 8 days, the plants were treated with $20 \mu \mathrm{M}$ ABA $((+/-)$-cis, trans-abscisic acid (Sigma, St. Louis, MO) dissolved in $\mathrm{NaOH}$ ), 57.1 $\mu \mathrm{M} \mathrm{NaOH}$ (control for ABA treatment), 20\% PEG-8000 (Sigma, St. Louis, MO), or milliQ water (PEG control) by adding these solutions to the Hoagland's solution for 27 hours; a time point chosen to mimic the parameters of Buchannan's treatment of the plants prior to cDNA microarray analysis [31].

Three groups of 10 plants each were harvested posttreatment as paired shoots and roots; the roots and shoots sequenced in each run are two parts from the same plants. Shoot and root tissue were quickly divided at the residual seed coat, flash frozen in liquid $\mathrm{N}_{2}$ and stored at $-80^{\circ} \mathrm{C}$ until used for RNA extraction. The hydroponic experiment was conducted three times over the course of several months in this manner with each experiment representing one biological replicate.

\section{RNA Extractions and Pooling}

Total RNA was extracted using the miRNEasy kit (Qiagen, Valencia, CA) from paired shoot/root samples; one sample per bucket per treatment per hydroponic experiment (Figure 1). Three equimolar RNA samples for a particular treatment from a single hydroponic experiment were combined and used to prepare cDNA for RNA-Seq analysis as described below.

\section{RNA-Seq cDNA Preparation}

cDNA was generated using the RNA-Seq kit according to the manufacturer's protocol (Illumina Inc., San Diego, CA). In short, poly-A RNA was isolated from total RNA and chemically fragmented. First and second strand synthesis were followed by end repair, and adenosines were added to the 3 ' ends. Adapters were ligated to the cDNA and $200 \pm 25$ bp fragments were gel purified and enriched by PCR. cDNA was quantified using the Qubit BroadRange Assay (Invitrogen, Carlsbad, CA), checked on a Bioanalyzer 2100 (Agilent Technologies, Santa Clara, CA) and run on the Illumina GAIIx Sequencer (Illumina Inc.) using version 4 reagents. Single-read sequences of length 51 bp were collected and have been deposited in GEO (GSE30249).

\section{Analysis of RNA-Seq Sequences}

Base calling on the GAIIx was performed by Illumina's Real Time Analysis (RTA) software to produce sequence files that were used for alignment and the determination of gene counts. Sequences were trimmed to $50 \mathrm{bp}$ and aligned to the sorghum genome (sbi1 downloaded from ftp://ftp.jgi-psf.org/pub/JGI_data/phytozome/v6.0/Sbicolor/assembly/) using the ELAND_rna algorithm and raw counts per gene returned using CASAVA v1.6 software according to the Illumina CASAVA1.6 User Guide. ELAND (Efficient Large-Scale Alignment of Nucleotide Databases) searches a set of large DNA files for a large number of short DNA reads allowing up to 2 errors per match. ELAND_rna required additional files to analyze RNA sequencing data including an abundant sequences file that contained sorghum chloroplast, mitochondria and repeat sequences, an exon coordinates file and a splice junctions file (these last two files were generated from Sbi1.4.gff3 downloaded from ftp://ftp.jgi-psf.org/ pub/JGI_data/phytozome/v6.0/Sbicolor/annotation/ using a combination of custom perl scripts and those provided with the CASAVA v1.6 package). All of the 
sorghum files necessary for alignment and determination of gene counts using the CASAVA V1.6 software are available upon request. edgeR [48-50] was used to simultaneously quantile normalize the raw counts for each run due to an upgrade to the Illumina RTA software (from v1.5 to v1.6) that resulted in higher sequence counts for our third biological replication. Quantile normalization for all Illumina runs was conducted once to allow for comparison across all samples, as described below. The raw counts from the output of CASAVA v1.6 were given to the edgeR package (version1.4.7) in $\mathrm{R}$ [48-50] and quantile normalized together within edgeR functions. edgeR finds changes between two or more groups when either or both groups contain replicates, by using a negative binomial distribution model and estimating genewise dispersions based on conditional maximum likelihood [48-50]. In edgeR, an appropriate object (d) was created by calling the DGEList function parameters as follows: counts $=$ matrix of raw counts, group $=$ list of order of columns in counts, lib.size $=$ NULL, remove. zeros = TRUE. A common dispersal of the counts was rendered using the estimateCommonDisp function on the previously made object (d). Next, analysis was performed on the desired pairs using the exactTest function (de.com). The genes found to be differentially expressed and with a p-value of less than 0.01 were retrieved using the function topTags; parameters used were de.com and $\mathrm{n}=\operatorname{sum}($ de.com\$table\$p.value < $0.01)$ ). Taking into consideration the 3 biological replicates for the pairs of samples (i.e. treatment and control), edgeR returned a list of differentially expressed genes, which were then filtered for a pvalue adjusted by multiple-hypothesis testing of less than 0.05 . Gene list results were filtered for genes with a median sequencing depth of $2 \mathrm{X}$ in at least one of the two samples compared (i.e. control or treatment) and a $\log _{2}$-fold change of $\geq 1$ or $\leq-1$. Gene counts were not normalized for gene length, as we did not compare expression levels across genes, but rather expression across treatments.

\section{Determination of Read Depth Cutoff Value for Differential Gene Expression}

Trends in the data were examined to identify an appropriate cutoff value for determination of differential gene expression. Approximately $40 \%$ of all expressed sorghum genes had between 5,001-50,000 mapped RNA-Seq reads (Additional File 13), and $\sim 30 \%$ were sequenced to a depth of 10-50X (Table 2). The distribution of read depth per gene was comparable across all runs with $>80 \%$ of transcriptionally active genes having more than 500 read counts (Additional File 13). At a read depth of $2 \mathrm{X}, 13,964$ genes were expressed in at least one tissue/ treatment combination (data not shown). Of the 26,466 annotated gene models detected in the present study with median sequencing depth of greater than zero (i.e. read counts for a gene were 0 for at most 1 run), 2,971 were expressed at a median read depth of less than $2 \mathrm{X}$ but greater than $0.5 \mathrm{X}$ in at least one tissue/treatment combination (data not shown). Thus $\sim 11.2 \%$ of the sorghum genes detected in this study either exhibit low expression in the present experimental conditions tested or represent background signal in the RNA-Seq method. Therefore, to minimize false positives while retaining genes of lower expression, a $2 \mathrm{X}$ median read depth cutoff in one of the two samples being compared (i.e., ABA-treated vs. $\mathrm{NaOH}$-treated) was chosen for examination of differential gene expression.

\section{qPCR Validation}

For each sample, $10 \mu \mathrm{g}$ total RNA was treated with Turbo DNA-free (Ambion, Austin, TX), $1 \mu \mathrm{g}$ of which was reverse transcribed in a $20 \mu \mathrm{L}$ volume using 200 units SuperScript III (Invitrogen) primed with random hexamers. The resulting cDNA was diluted to $200 \mu \mathrm{L}$ with water. Gene-specific primers were designed to span the last exon of the transcript using Primer3 software (http://frodo.wi.mit.edu/primer3/). Quantitative real time PCR was carried out in triplicate using the ABI Prism 7900HT Sequence Detection System on $1 \mu \mathrm{L}$ diluted cDNA, Power SYBR Green PCR Master Mix (Applied Biosystems, Carlsbad, CA) and primers at a final

Table 2 Number of Gene Models Binned by Median Sequencing Depth Cut-off

\begin{tabular}{|c|c|c|c|c|c|c|c|}
\hline & $0 \times S^{a}$ & $\leq 1 \times \mathrm{SD}$ & $1 x<S D \leq 2 x$ & $2 x<S D \leq 5 x$ & $5 x<S D \leq 10 x$ & $10 x<S D \leq 50 x$ & $>50 \times$ SD \\
\hline ABA-Treated Roots & 10004 & 5136 & 2026 & 3599 & 3816 & 7542 & 2022 \\
\hline $\mathrm{NaOH}$-Treated Roots & 9943 & 5158 & 2110 & 3625 & 3694 & 7547 & 2068 \\
\hline PEG-Treated Roots & 9674 & 5154 & 1987 & 3620 & 3792 & 7753 & 2165 \\
\hline $\mathrm{H}_{2} \mathrm{O}$-Treated Roots & 9925 & 5189 & 2115 & 3627 & 3673 & 7558 & 2058 \\
\hline ABA-Treated Shoots & 10639 & 5695 & 2072 & 3641 & 3784 & 6424 & 1890 \\
\hline $\mathrm{NaOH}$-Treated Shoots & 10462 & 5642 & 2053 & 3553 & 3736 & 6625 & 2074 \\
\hline PEG-Treated Shoots & 10033 & 5465 & 2058 & 3533 & 3776 & 7249 & 2031 \\
\hline $\mathrm{H}_{2} \mathrm{O}$-Treated Shoots & 10794 & 5800 & 2060 & 3647 & 3804 & 6251 & 1789 \\
\hline
\end{tabular}

${ }^{\mathrm{a}} \mathrm{SD}$ denotes sequencing depth calculated as the total number of bases mapped to a gene (exons only) divided by total gene (exon) length. 
concentration of $0.05 \mu \mathrm{M}$ each. Primer sequences are contained in Additional File 5. The $18 \mathrm{~S}$ primers and probe (TaqMan Ribosomal RNA Control Reagents kit, Applied Biosystems) were used at a final concentration of $0.025 \mu \mathrm{M}$, with $1 \mu \mathrm{L}$ diluted cDNA and TaqMan Universal PCR Master Mix (Applied Biosystems). PCR conditions were $2 \mathrm{~min}$ at $50^{\circ} \mathrm{C}$ and $10 \mathrm{~min}$ at $95^{\circ} \mathrm{C}$ followed by 47 cycles of $95^{\circ} \mathrm{C}$ for $15 \mathrm{sec}$ and $60^{\circ} \mathrm{C}$ for $1 \mathrm{~min}$ and the dissociation period of $95^{\circ} \mathrm{C}$ for $15 \mathrm{sec}, 60^{\circ} \mathrm{C}$ for 15 sec and $95^{\circ} \mathrm{C}$ for $15 \mathrm{sec}$. DNA amplification was monitored in real time using ABI Prism 7900HT Sequence Detection System software (v2.2). Amplification of $18 \mathrm{~S}$ rRNA was monitored as an endogenous control that was used to normalize template amounts. Control reactions in which reverse transcriptase was omitted did not give amplification signals above the threshold.

\section{SorghumCyc Pathway Enrichment Analysis}

SorghumCyc is a pathway/genome database that integrates genomic information with experimentally elucidated and electronically derived functional annotations to infer metabolic pathways in sorghum [146]. Using Z-score statistics, a method to determine how many standard deviations a given observation is from the standard mean, we performed an enrichment analysis on SorghumCyc data (ftp://ftp.gramene.org/pub/gramene/pathways/sorghumcyc (ver 1.0 beta)). Data were filtered such that gene models thought to occur on the sorghum scaffolds (name format Sb\#\#\#s\#\#\#\#\#) were removed. The Z-score was calculated as the quantity of the number of observed counts minus the expected counts, divided by the square root of the standard deviation of the expected counts for each pathway. The observed counts are defined as the number of DE genes within a pathway. The expected counts are determined by multiplying the number of genes in the DE gene list of interest by the number of genes within the pathway of interest and dividing this value by the number of unique genes in the collection of all pathways. SorghumCyc pathways were considered significantly enriched if the following criteria were met: $\mathrm{Z}$-score $\geq 2$, p-value $\leq$ 0.05 , and the expected number of genes for a family $>1$. Pathways within SorghumCyc are conveniently broken into reactions using data from SorghumCyc source files $(i$. $e$., pathways.dat, reactions.dat, enzrxns.dat, proteins.dat, and genes.dat). The ratio of reactions in a given pathway containing DE genes divided by the number of reactions within the pathway was then determined and considered an alternate method for determining possible pathway regulation.

\section{GO Enrichment Analysis of Differentially Expressed Gene} Sets

GO enrichment was determined using the goseq package [156] in $\mathrm{R}$ using annotations from agriGO (http://
bioinfo.cau.edu.cn/agriGO/) [157]. The agriGO genes$\mathrm{GO}$ annotation pairs were filtered such that gene models thought to occur on the sorghum scaffolds (name format Sb\#\#\#s\#\#\#\#\#) were removed; gene models were condensed by removing the number trailing the "." and retaining only unique gene-GO annotation pairs. Each unique gene within a GO category was allowed to contribute to the enrichment of that category, regardless of the number of categories it is annotated to. goseq compensates for selection bias (i.e. length of the genes within different categories) and determines significance based on an extension of the hypergeometric distribution (Wallenius non-central hypergeometric distribution) [156]. Categories were considered significant if the pvalue $\leq 0.05$.

\section{Transcription Factor Analysis}

Transcription factor information and protein sequences were downloaded from PlnTFDB (http://plntfdb.bio.unipotsdam.de/v3.0/) [134,135]. The protein sequences were blasted against the sorghum genome to determine the JGI accepted gene identification; the top hits with evalue less than 0.1 were retained. Transcription factors from PlnTFDB were combined with those from PlantTFDB (http://planttfdb.cbi.pku.edu.cn/download/ gene_model_family/Sbi) [136-138] and GrassTFDB (http://grassius.org/browsefamily.html?species=Sorghum) [139]. Annotations from members of the same TF family were collapsed if the names were the same, but formatted differently (e.g. JUMONJI and Jumonji or MYBrelated and MYB_related). Enrichment analysis was performed using Z-score analysis as defined above. Transcription factors were considered significant if the following criteria were met: Z-score $\geq 2$, p-value $\leq 0.05$, and the expected number of genes for a family $>1$.

\section{cis-Acting Promoter Element Analysis}

Promoter elements were downloaded from PlantCARE (http://bioinformatics.psb.ugent.be/webtools/plantcare/ html/) [121,122] and PLACE (http://www.dna.affrc.go.jp/ PLACE/index.html) [123,124]. These databases were used as they allowed for easily downloadable, queryable, and manipulatable files that could be used to run an analysis in-house. The element names were collapsed if the sequences for them were identical. Promoter sequences (1000 bp) for all sorghum genes were determined based on the Sbi1.4 annotation and downloaded from Gramene BioMart (http://gramene.org/biomart/ martview). As current annotation is not refined, some genes lack complete 5'-UTR lengths, and, for these genes, the 1000 bp upstream sequences analyzed will contain partial or complete 5'-UTR sequence. cis-elements were located in the upstream regions by matching in $\mathrm{R}$; location and number were recorded. 
Enrichment was considered significant if the following criteria were met: Z-score $\geq 2$, a hypergeometric distribution adjusted p-value of $\leq 0.05$, and the expected number of genes for a family $>1$.

\section{Ortholog Analysis}

Gene descriptions and putative ortholog pairs from the Arabidopsis, rice, sorghum and maize genomes were derived from Gramene BioMart (http://gramene.org/biomart/martview) [146]. Manipulations were performed in R. The method is summarized in Figure 7. Sorghum DE genes were filtered for those with unknown function by searching for the terms 'hypothetical', 'expressed', 'predicted' and 'uncharacterized'. Using the data from Gramene, we determined if these genes contained orthologs in the species of interest and whether all orthologs designated for a particular gene were of unknown function. This smaller listing of genes was then assayed for previously published drought responsiveness in the nonsorghum species. The resulting $S b$-ortholog pairs are of unknown function in sorghum and the non-sorghum species of interest and responsive to drought in both species. We did not require that the gene expression across the different species lists occur in the same direction, only that the genes were $\mathrm{DE}$, as genes within single species can range in expression from repression to induction depending on the severity of the drought stress [30].

\section{Network Analysis}

Network analysis was performed in R using SorghumCyc pathways (http://www.gramene.org/pathway/sorghumcyc.html) [146] that had been manually collapsed. This collapse consisted of combining related pathways (e.g. alanine biosynthesis II and III or cytokinins 7-Nglucoside, cytokinins 9- $\mathrm{N}$-glucoside, and cytokinins- $\mathrm{O}$ glucoside biosynthesis). The pathways were filtered such that only genes of interest were considered as edges between nodes (pathways). Matrices were generated that contained the paired pathway names and the number of DE genes in common between them. The information was then imported into Cytoscape [158,159] to visualize the networks.

\section{Additional material}

Additional file 1: Lane by lane summary of RNA-Seq data. ${ }^{\dagger}$ Read mapping to splice junctions included within the total number of reads mapped to genes.

Additional file 2: Pearson correlation coefficients for roots and shoots across all runs

Additional file 3: Differentially expressed genes in treatment vs. control roots and shoots based on a $2 \mathrm{X}$ sequencing depth.

${ }^{a}$ Confidences refer to those assigned to the gene models by Patterson et. al [43]. ${ }^{b} \mathrm{AB} / 3 \mathrm{VP} 1$ - proteins containing a B3 domain and named after the founding members (ABA INSENSITIVE 3 and VIVIPAROUS1); AP2 Apetela2-like proteins that contain one repeated AP2/ERF domain; AP2EREBP - Apetela2 and Ethylene-responsive element binding proteins containing two repeated AP2/ERF domains; ARF - auxin response factor family members; ARR-B - members of the type-B phospho-accepting response regulator family; AUX/IAA - auxin/indole-3-acetic acid family members controlled by auxin-responsive elements (AuxREs); B3 Superfamily that encompasses the auxin response factor family, and the LAV, RAV and REM family containing an 110 amino acid region called the B3 domain; bHLH - basic helix-loop-helix protein; bZIP - basic leucine zipper protein; C2C2-CO-like - similar to "CO-like"; C2C2-Dof - proteins containing DNA-binding with one finger domain and a highly conserved DNA-binding domain, which includes a single C2-C2 zinc finger; C2C2GATA - GATA-binding proteins containing one or two highly conserved zinc finger DNA-binding domains; C2C2-YABBY - proteins containing a C2C2 zinc finger-like domain towards the amino terminus and a helixloop-helix (YABBY) domain; $\mathrm{C} 2 \mathrm{H} 2$ - proteins containing zinc finger domains with a secondary structure stabilized by a zinc ion bound to the Cys and His residues of the finger; $\mathrm{C} 3 \mathrm{H}$ - proteins containing a Cys3His zinc finger domain; CCAAT - proteins contained within the NF-A complex that recognize CCAAT box motifs; CCAAT-HAP2 - HAP2 proteins of the heterotrimeric CCAAT-box-binding complex (HAP2, HAP3, and HAP5); CO-like - CONSTANS-like proteins, containing both a zinc-finger and CCT (CO, CO-like, TOC1) domain; CPP - cysteine-rich polycomb-like proteins containing one or two Cys-rich domains; DBB - proteins

containing double B-box zinc finger domains; Dof - proteins containing DNA-binding with one finger domain; EIL - EIN-3-like transcription factors involved in ethylene signaling; ERF - ethylene-responsive factors; FAR1 far-red-impaired response family members; G2-like - proteins similar to G2 (maize); GATA - proteins that interact with conserved WGATAR; GeBP - proteins similar to GL1 enhancer binding protein and containing a central region with no known motifs and a C-terminal region with a putative leucine-zipper motif; GNAT - Gcn5-related N-acetyltransferase superfamily members; GRAS - named for GAI, RGA, SCR family members; GRF - proteins containing the same QLQ and WRC domains found in GROWTH-REGULATING FACTOR1 (GRF1); HB - similar to "Homeobox"; HDZIP - proteins containing a homeodomain and leucine zipper motif; HMG - proteins containing high-mobility-group boxes initially identified as DNA-binding domains; Homeobox - homeobox proteins; HSF - heat shock factor proteins; Jumonji - proteins that contain JmjN and JmjC domains and may be protein hydroxylases that catalyse a novel histone modification; LBD and LOB-LATERAL ORGAN BOUNDARIES domain containing proteins which bind to GCGGCG; LSD - proteins that contain three zinc finger domains; M-type - similar to "MADS"; MADS -

MINICHROMOSOME MAINTENANCE 1 (MCM1) from S. cerevisiae AGAMOUS (AG) from Arabidopsis thaliana, DEFICIENS (DEF) from Antirrhinum majus and SERUM RESPONSE FACTOR (SRF) from Homo sapiens) family members: MBF1 - proteins similar to multiprotein bridging factor 1 and mediators of transcriptional activation by bridging between an activator and a TATA-box binding protein (TBP); MIKC - type-II MADS-box containing proteins; mTERF - proteins containing repetitions of a 30 amino acid module, the mTERF motif, containing leucine zipper-like heptads; MYB proteins containing the MYB (from the oncogene of avian myeloblastosis virus) domain; MYB-related - proteins containing MYB-related domains; NAC - named for NAM, ATAF, and CUC family members; NF-YA - the A subunit of the NF-Y complex that recognizes CCAAT box motifs; NF-YB the B subunit of the NF-Y complex that recognizes CCAAT box motifs; Nin-like - nodule inception-like proteins; OFP - ovate family proteins contain a conserved C-terminal domain; Orphans - transcription factors that don't belong to any of the other families - from GrassTFDB; PHD proteins containing a Plant Homeo Domain finger that resembles the metal binding RING domain (Cys3-His-Cys4) and FYVE domain; PLATZ proteins similar to PLATZ1 (plant AT-rich sequence- and zinc-binding protein 1) zinc-dependent DNA-binding protein; Pseudo ARR-B - type-B phospho-accepting response regulator proteins; RAV - proteins containing both a B3 domain and a single AP2/ERF domain; RWP-RK proteins containing a RWP-RK domain; SBP - proteins encoding a conserved protein domain of 76 amino acids in length (SBP-domain); SET - proteins containing a 130-residue SET domain (named after three Drosophilia genes involved in epigenetic processes, Su(var), E(z) and trithorax); Sigma70-like - proteins similar to sigma70; SNF2 - proteins with 
seven characteristic blocks comprising the helicase region; TALE - threeamino-acid-loop-extension class of homeoproteins contains the KNOTTED-like homeodomain (KNOX) and BEL1-like Homeodomain (BELL) members; TAZ - proteins containing a TAZ2 zinc finger; TCP - proteins containing the TCP (from teosinte branched 1from maize, CYCLOIDEA from snapdragon, and the PROLIFERATING CELL FACTORS 1 and 2 from rice) domain, a 59-amino acid basic helix-loop-helix motif; Tify - proteins containing a TIFY domain (named for the most conserved amino acids); Trihelix - proteins containing helix-loop-helix-loop-helix domains; TUB proteins containing C-terminal tubby domains; Uncategorized transcription factors that don't belong to any of the other families GrassTFDB and PInTFDB; WOX - homeobox proteins containing a conserved DNA-binding homeodomain; WRKY - proteins containing the WRKYGQK sequence followed by a $\mathrm{C} 2 \mathrm{H} 2$ or $\mathrm{C} 2 \mathrm{HC}$ zinc finger motif; YABBY - similar to "C2C2-YABBY"; ZF-HD - zinc finger homeodomain proteins

Additional file 4: All genes differentially expressed under ABA- or PEG-treatment

Additional file 5: Oligonucleotides used for qRT-PCR. ${ }^{\mathrm{a}} \mathrm{GenelDs}$ in bold have unknown protein function. ${ }^{\mathrm{b}} \mathrm{qPCR}$ results comparing treated vs. control samples; passed - qPCR results agreed with RNA-Seq data; failed - GPCR results did not agree with RNA-Seq data.

Additional file 6: Enrichment p-values for GO biological processes categories. ${ }^{a} \mathrm{GO}$ categories falling under Other do so because they are found as enriched for groups of DE genes which are not easily grouped according to differential expression in tissue or treatment.

Additional file 7: SorghumCyc pathway Z-score enrichment analysis for genes differentially expressed in treatment vs. control roots and shoots. ${ }^{~}$ Observed Counts $=$ The number of DE genes found within a given pathway. ${ }^{2}$ Expected Counts $=$ The number of DE genes expected within a given pathway based on the size of the pathway and DE gene list (see Methods). ${ }^{3} \mathrm{~A} Z$-score $\geq 2$ with a corresponding $\mathrm{p}$-value $\leq 0.05$ is indicative of an enriched pathway.

Additional file 8: Ratio of reactions containing differentially expressed genes to the total number of reactions within annotated

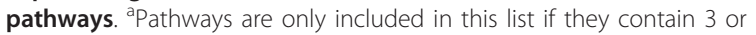
more reactions.

Additional file 9: $p$-Values for cis-element enrichment within 1000 bp from the transcription start sites for differentially expressed genes in response to ABA- and PEG-treatment. $+B(C G T) ; D(A G T) ; H$ (ACT); K (GT); $M(A C)$; N (ACGT); R (AG); $S(C G) ; V(A C G) ; W(A T)$; Y (CT)

Additional file 10: Ortholog gene pairs of unknown function important in drought response. ${ }^{\mathrm{a}}[145] ;{ }^{\mathrm{b}}[26] ;{ }^{\mathrm{c}}[13] ;{ }^{\mathrm{d}}[17] ;{ }^{\mathrm{e}}[30]$ Additional file 11: p-Values for cis-element enrichment in $1000 \mathrm{bp}$ upstream of the transcriptional start site for sorghum genes with unknown function conserved in function and expression across species. +B (CGT); D (AGT); H (ACT); K (GT); M (AC); N (ACGT); R (AG); $S$ (CG); V (ACG); W (AT); Y (CT)

Additional file 12: $p$-Values for cis-element enrichment in 1000 bp upstream of the transcriptional start site for rice, maize, and Arabidopsis genes with unknown function conserved in function and expression to sorghum. $+B(C G T) ; D(A G T) ; H(A C T) ; K(G T) ; M(A C)$; $N$ (ACGT); R (AG); S (CG); V (ACG); W (AT); Y (CT)

Additional file 13: Number of genes within read count bins

\section{Acknowledgements}

We would like to acknowledge Eun-Gyu No for generating the RNA-Seq clusters and running them on the Illumina GAllx machine. We thank Julie McCollum, Millie Burrell, and Natalie Unruh for helpful comments and discussion. This study was supported by USDA ARS 1907-21000-030 (D.W.), NSF IOS-0703908 (D.W.), US Department of Agriculture-Agricultural Research Service (R.R.K.), and Texas AgriLife Research (P.E.K.).

\section{Author details}

'Department of Horticulture, Texas A\&M University, College Station, TX 77843, USA. ${ }^{2}$ Cold Spring Harbor Laboratory, Cold Spring Harbor, NY 11724 USA. ${ }^{3}$ USDA-ARS, Southern Plains Agricultural Research Center, College Station, TX 77843, USA. ${ }^{4}$ USDA-ARS, Robert W. Holley Center for Agriculture and Health, Cornell University, Ithaca, NY 14853, USA.

\section{Authors' contributions}

DVD generated the RNA-Seq CDNA and DE gene lists, performed ciselement, GO, SorghumCyc pathway, and transcription factor analysis, and drafted the manuscript. MKM contributed to the SorghumCyc pathway analysis and reviewed the manuscript. AO developed alternative scripts to process RNA-Seq data and compare the results to sorghum genomic annotations and reviewed the manuscript. RRK contributed to the interpretation of the data and helped draft the manuscript. SK performed GO enrichment analysis, retrieved gene descriptions and putative ortholog pairs, and reviewed the manuscript. DW contributed to the experimental design, interpretation of the data, and helped draft the manuscript. PEK contributed to the experimental design, processed the RNA-Seq data to generate raw counts per gene, contributed to the interpretation of the data, and helped draft the manuscript. All authors read and approved the final manuscript.

Received: 23 June 2011 Accepted: 18 October 2011

Published: 18 October 2011

\section{References}

1. Boyer JS: Plant productivity and environment. Science 1982, 218(4571):443-448.

2. Gleick PH: Global freshwater resources: soft-path solutions for the 21st century. Science 2003, 302(5650):1524-1528.

3. Johnson N, Revenga C, Echeverria J: Ecology. Managing water for people and nature. Science 2001, 292(5519):1071-1072.

4. Amber D: Genetic responses to drought. Scientist 2000, , 14: 18-19.

5. Bohnert HJ, Nelson DE, Jensen RG: Adaptations to environmental stresses. Plant Cell 1995, 7(7):1099-1111.

6. Bray EA: Plant responses to water deficit. Trends Plant Sci 1997, 2: 48-54

7. Cushman JC, Bohnert HJ: Genomic approaches to plant stress tolerance. Curr Opin Plant Biol 2000, 3(2):117-124.

8. Holmberg N, Bulow L: Improving stress tolerance in plants by gene transfer. Trends Plant Sci 1998, 3: 61-66.

9. Ludlow MM, Muchow RC: A critical evaluation of traits for improving crop yields in water-limited environments. Adv Agron 1990, , 43: 107-153.

10. Shinozaki K, Yamaguchi-Shinozaki K: Gene expression and signal transduction in water-stress response. Plant Physiol 1997, 115(2):327-334.

11. Zhu J, Hasegawa PM, Bressan RA: Molecular aspects of osmotic stress in plants. Crit Rev Plant Sci 1997, , 16: 253-277.

12. Doggett $\mathrm{H}$ : Yield increase from sorghum hybrids. Nature 1967 216(5117):798-799

13. Hoth S, Morgante M, Sanchez JP, Hanafey MK, Tingey SV, Chua NH: Genome-wide gene expression profiling in Arabidopsis thaliana reveals new targets of abscisic acid and largely impaired gene regulation in the abi1-1 mutant. J Cell Sci 2002, 115(Pt 24):4891-4900.

14. Kilian J, Whitehead D, Horak J, Wanke D, Weinl S, Batistic O, D'Angelo C, Bornberg-Bauer E, Kudla J, Harter K: The AtGenExpress global stress expression data set: protocols, evaluation and model data analysis of UV-B light, drought and cold stress responses. Plant J 2007, 50(2):347-363.

15. Kreps JA, Wu Y, Chang HS, Zhu T, Wang X, Harper JF: Transcriptome changes for Arabidopsis in response to salt, osmotic, and cold stress. Plant Physiol 2002, 130(4):2129-2141.

16. Liu HH, Tian X, Li YJ, Wu CA, Zheng CC: Microarray-based analysis of stress-regulated microRNAs in Arabidopsis thaliana. RNA 2008, 14(5):836-843.

17. Matsui A, Ishida J, Morosawa T, Mochizuki Y, Kaminuma E, Endo TA, Okamoto M, Nambara E, Nakajima M, Kawashima M, et al: Arabidopsis transcriptome analysis under drought, cold, high-salinity and ABA treatment conditions using a tiling array. Plant Cell Physiol 2008, 49(8):1135-1149.

18. Matsui A, Ishida J, Morosawa T, Okamoto M, Kim JM, Kurihara Y, Kawashima M, Tanaka M, To TK, Nakaminami K, et al: Arabidopsis tiling 
array analysis to identify the stress-responsive genes. Methods Mol Biol 2010, 639:141-155.

19. Oono Y, Seki M, Nanjo T, Narusaka M, Fujita M, Satoh R, Satou M, Sakurai T, Ishida J, Akiyama K, et al: Monitoring expression profiles of Arabidopsis gene expression during rehydration process after dehydration using ca. 7000 full-length cDNA microarray. Plant J 2003, 34(6):868-887.

20. Seki M, Narusaka M, Abe H, Kasuga M, Yamaguchi-Shinozaki K, Carninci $P$, Hayashizaki Y, Shinozaki K: Monitoring the Expression Pattern of 1300 Arabidopsis Genes under Drought and Cold Stresses by Using a FullLength cDNA Microarray. Plant Cell 2001, 13(1):61-72.

21. Seki M, Ishida J, Narusaka M, Fujita M, Nanjo T, Umezawa T, Kamiya A, Nakajima M, Enju A, Sakurai T, et al: Monitoring the expression pattern of around 7,000 Arabidopsis genes under ABA treatments using a fulllength cDNA microarray. Funct Integr Genomic 2002, 2(6):282-291.

22. Seki M, Narusaka M, Ishida J, Nanjo T, Fujita M, Oono Y, Kamiya A, Nakajima M, Enju A, Sakurai T, et al: Monitoring the expression profiles of 7000 Arabidopsis genes under drought, cold and high-salinity stresses using a full-length cDNA microarray. Plant J 2002, 31(3):279-292.

23. Degenkolbe T, Do PT, Zuther E, Repsilber D, Walther D, Hincha DK, Kohl Kl: Expression profiling of rice cultivars differing in their tolerance to longterm drought stress. Plant Mol Biol 2009, 69(1-2):133-153.

24. Rabbani MA, Maruyama K, Abe H, Khan MA, Katsura K, Ito Y, Yoshiwara K, Seki M, Shinozaki K, Yamaguchi-Shinozaki K: Monitoring expression profiles of rice genes under cold, drought, and high-salinity stresses and abscisic acid application using cDNA microarray and RNA gel-blot analyses. Plant Physiol 2003, 133(4):1755-1767.

25. Zhao B, Liang R, Ge L, Li W, Xiao H, Lin H, Ruan K, Jin Y: Identification of drought-induced microRNAs in rice. Biochem Biophys Res Commun 2007, 354(2):585-590.

26. Zhou J, Wang X, Jiao Y, Qin Y, Liu X, He K, Chen C, Ma L, Wang J, Xiong L, et al: Global genome expression analysis of rice in response to drought and high-salinity stresses in shoot, flag leaf, and panicle. Plant Mol Biol 2007, 63(5):591-608.

27. Zhou L, Liu Y, Liu Z, Kong D, Duan M, Luo L: Genome-wide identification and analysis of drought-responsive microRNAs in Oryza sativa. J Exp Bot 2010, 61(15):4157-4168.

28. Hayano-Kanashiro C, Calderon-Vazquez C, Ibarra-Laclette E, HerreraEstrella L, Simpson J: Analysis of gene expression and physiological responses in three Mexican maize landraces under drought stress and recovery irrigation. PLOS One 2009, 4(10):e7531.

29. Luo M, Liu J, Lee RD, Scully BT, Guo B: Monitoring the expression of maize genes in developing kernels under drought stress using oligomicroarray. J Integr Plant Biol 2010, 52(12):1059-1074.

30. Zheng J, Fu J, Gou M, Huai J, Liu Y, Jian M, Huang Q, Guo X, Dong Z, Wang $H$, et al: Genome-wide transcriptome analysis of two maize inbred lines under drought stress. Plant Mol Biol 2010, 72(4-5):407-421.

31. Buchanan CD, Lim S, Salzman RA, Kagiampakis I, Morishige DT, Weers BD, Klein RR, Pratt LH, Cordonnier-Pratt MM, Klein PE, et al: Sorghum bicolor's transcriptome response to dehydration, high salinity and ABA. Plant Mol Biol 2005, 58(5):699-720.

32. Huang D, Wu W, Abrams SR, Cutler AJ: The relationship of droughtrelated gene expression in Arabidopsis thaliana to hormonal and environmental factors. J Exp Bot 2008, 59(11):2991-3007.

33. Zhang M, Duan L, Tian X, He Z, Li J, Wang B, Li Z: Uniconazole-induced tolerance of soybean to water deficit stress in relation to changes in photosynthesis, hormones and antioxidant system. J Plant Physiol 2007 164(6):709-717.

34. Wang C, Yang A, Yin H, Zhang J: Influence of water stress on endogenous hormone contents and cell damage of maize seedlings. $J$ Integr Plant Biol 2008, 50(4):427-434.

35. Hubbard KE, Nishimura N, Hitomi K, Getzoff ED, Schroeder J: Early abscisic acid signal transduction mechanisms: newly discovered components and newly emerging questions. Genes Dev 2010, 24(16):1695-1708.

36. Seki M, Umezawa T, Urano K, Shinozaki K: Regulatory metabolic networks in drought stress responses. Curr Opin Plant Biol 2007, 10(3):296-302.

37. Shinozaki K, Yamaguchi-Shinozaki K, Seki M: Regulatory network of gene expression in the drought and cold stress responses. Curr Opin Plant Biol 2003, 6(5):410-417

38. Wasilewska A, Vlad F, Sirichandra C, Redko Y, Jammes F, Valon C, Frei dit Frey $\mathrm{N}$, Leung J: An update on abscisic acid signaling in plants and more. Mol Plant 2008, 1(2):198-217.
39. Leung $\mathrm{H}$ : Stressed genomics-bringing relief to rice fields. Curr Opin Plant Biol 2008, 11(2):201-208.

40. Park SJ, Huang $\mathrm{YH}$, Ayoubi P: Identification of expression profiles of sorghum genes in response to greenbug phloem-feeding using CDNA subtraction and microarray analysis. Planta 2006, 223(5):932-947.

41. Salzman RA, Brady JA, Finlayson SA, Buchanan CD, Summer EJ, Sun F, Klein PE, Klein RR, Pratt LH, Cordonnier-Pratt MM, et al: Transcriptional profiling of sorghum induced by methyl jasmonate, salicylic acid, and aminocyclopropane carboxylic acid reveals cooperative regulation and novel gene responses. Plant Physiol 2005, 138(1):352-368.

42. Zhu-Salzman K, Salzman RA, Ahn JE, Koiwa H: Transcriptional regulation of sorghum defense determinants against a phloem-feeding aphid. Plant Physiol 2004, 134(1):420-431.

43. Paterson AH, Bowers JE, Bruggmann R, Dubchak I, Grimwood J, Gundlach H, Haberer G, Hellsten U, Mitros T, Poliakov A, et al: The Sorghum bicolor genome and the diversification of grasses. Nature 2009, 457(7229):551-556.

44. Coleman SJ, Zeng Z, Wang K, Luo S, Khrebtukova I, Mienaltowski MJ, Schroth GP, Liu J, MacLeod JN: Structural annotation of equine proteincoding genes determined by mRNA sequencing. Anim Genet 2010, 41 Suppl 2:121-130

45. Lu T, Lu G, Fan D, Zhu C, Li W, Zhao Q, Feng Q, Zhao Y, Guo Y, Huang X, et al: Function annotation of the rice transcriptome at single-nucleotide resolution by RNA-seq. Genome Res 2010, 20(9):1238-1249.

46. Severin AJ, Woody JL, Bolon YT, Joseph B, Diers BW, Farmer AD, Muehlbauer GJ, Nelson RT, Grant D, Specht JE, et al: RNA-Seq Atlas of Glycine max: a guide to the soybean transcriptome. BMC Plant Biol 2010, 10:160.

47. Yassour M, Kaplan T, Fraser HB, Levin JZ, Pfiffner J, Adiconis X, Schroth G, Luo S, Khrebtukova I, Gnirke A, et al: Ab initio construction of a eukaryotic transcriptome by massively parallel mRNA sequencing. Proc Natl Acad Sci USA 2009, 106(9):3264-3269.

48. Robinson MD, McCarthy DJ, Smyth GK: edgeR: a Bioconductor package for differential expression analysis of digital gene expression data. Bioinformatics 2010, 26(1):139-140.

49. Robinson MD, Smyth GK: Moderated statistical tests for assessing differences in tag abundance. Bioinformatics 2007, 23(21):2881-2887.

50. Robinson MD, Smyth GK: Small-sample estimation of negative binomial dispersion, with applications to sage data. Biostatistics 2008, 9(2):321-332

51. Bruno VM, Wang Z, Marjani SL, Euskirchen GM, Martin J, Sherlock G, Snyder M: Comprehensive annotation of the transcriptome of the human fungal pathogen Candida albicans using RNA-seq. Genome Res 2010, 20(10):1451-1458

52. Marioni JC, Mason CE, Mane SM, Stephens M, Gilad Y: RNA-seq: an assessment of technical reproducibility and comparison with gene expression arrays. Genome Res 2008, 18(9):1509-1517.

53. Fu X, Fu N, Guo S, Yan Z, Xu Y, Hu H, Menzel C, Chen W, Li Y, Zeng R, et al: Estimating accuracy of RNA-Seq and microarrays with proteomics. BMC Genomics 2009, 10:161.

54. Li P, Ponnala L, Gandotra N, Wang L, Si Y, Tausta SL, Kebrom TH, Provart N, Patel $R$, Myers $C R$, et al: The developmental dynamics of the maize leaf transcriptome. Nat Genet 2010, 42(12):1060-1067.

55. Arend M, Schnitzler JP, Ehlting B, Hansch R, Lange T, Rennenberg H, Himmelbach A, Grill E, Fromm J: Expression of the Arabidopsis mutant $A B / 1$ gene alters abscisic acid sensitivity, stomatal development, and growth morphology in gray poplars. Plant Physiol 2009, 151(4):2110-2119.

56. LeNoble ME, Spollen WG, Sharp RE: Maintenance of shoot growth by endogenous $A B A$ : genetic assessment of the involvement of ethylene suppression. J Exp Bot 2004, 55(395):237-245.

57. Parent B, Hachez C, Redondo E, Simonneau T, Chaumont Fo, Tardieu Fo: Drought and abscisic acid effects on aquaporin content translate into changes in hydraulic conductivity and leaf growth rate: $A$ trans-scale approach. Plant Physiol 2009, 149(4):2000-2012.

58. Gocal GF, Pharis RP, Yeung EC, Pearce D: Changes after decapitation in concentrations of indole-3-acetic acid and abscisic acid in the larger axillary bud of Phaseolus vulgaris L. cv Tender Green. Plant Physiol 1991, 95(2):344-350.

59. Pearce DW, Taylor JS, Robertson JM, Harker KN, Daly EJ: Changes in abscisic acid and indole-3-acetic acid in axillary buds of Elytrigia repens released from apical dominance. Physiol Plantarum 1995, 94(1):110-116. 
60. Rinne $P$, Welling $A$, Kaikuranta $P$ : Onset of freezing tolerance in birch (Betula pubescens Ehrh.) involves LEA proteins and osmoregulation and is impaired in an ABA-deficient genotype. Plant, Cell \& Environ 1998, 21(6):601-611.

61. Rinne Pi, Tuominen $\mathrm{H}$, Junttila $\mathrm{O}$ : Seasonal changes in bud dormancy in relation to bud morphology, water and starch content, and abscisic acid concentration in adult trees of Betula pubescens. Tree Physiol 1994, 14(6):549-561

62. Ruonala R, Rinne PL, Baghour M, Moritz T, Tuominen H, Kangasjarvi J: Transitions in the functioning of the shoot apical meristem in birch (Betula pendula) involve ethylene. Plant J 2006, 46(4):628-640.

63. Stafstrom JP, Ripley BD, Devitt ML, Drake B: Dormancy-associated gene expression in pea axillary buds. Cloning and expression of PsDRM1 and PsDRM2. Planta 1998, 205(4):547-552.

64. Tamas IA, Ozbun JL, Wallace DH, Powell LE, Engels CJ: Effect of fruits on dormancy and abscisic acid concentration in the axillary buds of Phaseolus vulgaris L. Plant Physiol 1979, 64(4):615-619.

65. Welling A, Kaikuranta P, Rinne P: Photoperiodic induction of dormancy and freezing tolerance in Betula pubescens. Involvement of $A B A$ and dehydrins. Physiol Plantarum 1997, 100(1):119-125.

66. Gubler F, Millar AA, Jacobsen JV: Dormancy release, ABA and pre-harvest sprouting. Curr Opin Plant Biol 2005, 8(2):183-187.

67. De Smet I, Zhang H, Inze D, Beeckman T: A novel role for abscisic acid emerges from underground. Trends Plant Sci 2006, 11(9):434-439.

68. Chinnusamy V, Gong Z, Zhu JK: Abscisic acid-mediated epigenetic processes in plant development and stress responses. J Integr Plant Biol 2008, 50(10):1187-1195.

69. Hand SC, Menze MA, Toner M, Boswell L, Moore D: LEA proteins during water stress: not just for plants anymore. Annu Rev Physiol 2011, 73:115-134.

70. Rorat T: Plant dehydrins - Tissue location, structure and function. Cellular \&amp; Molecular Biology Letters 2006, 11(4):536-556.

71. Wang W, Vinocur B, Altman A: Plant responses to drought, salinity and extreme temperatures: towards genetic engineering for stress tolerance. Planta 2003, 218(1):1-14.

72. Alvarez S, Marsh EL, Schroeder SG, Schachtman DP: Metabolomic and proteomic changes in the xylem sap of maize under drought. Plant Cell Environ 2008, 31(3):325-340.

73. Ashburner M, Ball CA, Blake JA, Botstein D, Butler H, Cherry JM, Davis AP, Dolinski K, Dwight SS, Eppig JT, et al: Gene ontology: tool for the unification of biology. The Gene Ontology Consortium. Nat Genet 2000, 25(1):25-29.

74. Hey SJ, Byrne E, Halford NG: The interface between metabolic and stress signalling. Ann Bot 2010, 105(2):197-203.

75. Chinnusamy V, Schumaker K, Zhu JK: Molecular genetic perspectives on cross-talk and specificity in abiotic stress signalling in plants. J Exp Bot 2004, 55(395):225-236.

76. Yamaguchi-Shinozaki K, Shinozaki K: Transcriptional regulatory networks in cellular responses and tolerance to dehydration and cold stresses. Annu Rev Plant Biol 2006, 57:781-803.

77. Mou Z, Wang X, Fu Z, Dai Y, Han C, Ouyang J, Bao F, Hu Y, Li J: Silencing of phosphoethanolamine $\mathrm{N}$-methyltransferase results in temperaturesensitive male sterility and salt hypersensitivity in Arabidopsis. Plant Cell 2002, 14(9):2031-2043.

78. Xing W, Rajashekar CB: Glycine betaine involvement in freezing tolerance and water stress in Arabidopsis thaliana. Environ Exp Bot 2001, 46(1):21-28.

79. Hanson AD, Rathinasabapathi B, Rivoal J, Burnet M, Dillon MO, Gage DA: Osmoprotective compounds in the Plumbaginaceae: a natural experiment in metabolic engineering of stress tolerance. Proc Natl Acad Sci USA 1994, 91(1):306-310.

80. Kavi Kishor PB, Sangam S, Amrutha RN, Sri Laxmi P, Naidu KR, Rao KRSS, Rao S, Reddy KJ, Theriappan P, Sreenivasulu N: Regulation of proline biosynthesis, degradation, uptake and transport in higher plants: Its implications in plant growth and abiotic stress tolerance. Curr Sci India 2005, 88(3):424-438.

81. Szabados L, Savouré A: Proline: A multifunctional amino acid. Trends Plant Sci 2010, 15(2):89-97.

82. Verbruggen $\mathrm{N}$, Hermans $\mathrm{C}$ : Proline accumulation in plants: A review. Amino Acids 2008, 35(4):753-759.

83. Barnett NM, Naylor AW: Amino acid and protein metabolism in bermuda grass during water stress. Plant Physiol 1966, 41(7):1222-1230.
84. Nambara E, Kawaide H, Kamiya $Y$, Naito S: Characterization of an Arabidopsis thaliana mutant that has a defect in $\mathrm{ABA}$ accumulation: ABA-dependent and ABA-independent accumulation of free amino acids during dehydration. Plant Cell Physiol 1998, 39(8):853-858.

85. Rhodes D, Handa S, Bressan RA: Metabolic changes associated with adaptation of plant cells to water stress. Plant Physiol 1986, 82(4):890-903.

86. Urano K, Maruyama K, Ogata Y, Morishita Y, Takeda M, Sakurai N, Suzuki H, Saito K, Shibata D, Kobayashi M, et al: Characterization of the ABAregulated global responses to dehydration in Arabidopsis by metabolomics. Plant J 2009, 57(6):1065-1078.

87. Malatrasi M, Corradi M, Svensson J, Close T, Gulli M, Marmiroli N: A branched-chain amino acid aminotransferase gene isolated from Hordeum vulgare is differentially regulated by drought stress. Theor Appl Genet 2006, 113(6):965-976.

88. Joshi V, Joung JG, Fei Z, Jander G: Interdependence of threonine, methionine and isoleucine metabolism in plants: accumulation and transcriptional regulation under abiotic stress. Amino Acids 2010, 39(4):933-947.

89. Seo M, Hanada A, Kuwahara A, Endo A, Okamoto M, Yamauchi Y, North $H$, Marion-Poll A, Sun TP, Koshiba T, et al: Regulation of hormone metabolism in Arabidopsis seeds: phytochrome regulation of abscisic acid metabolism and abscisic acid regulation of gibberellin metabolism. Plant J 2006, 48(3):354-366.

90. Cowan AK, Freeman M, Bjorkman PO, Nicander B, Sitbon F, Tillberg E: Effects of senescence-induced alteration in cytokinin metabolism on source-sink relationships and ontogenic and stress-induced transitions in tobacco. Planta 2005, 221(6):801-814.

91. Havlova M, Dobrev Pl, Motyka V, Storchova H, Libus J, Dobra J, Malbeck J, Gaudinova A, Vankova R: The role of cytokinins in responses to water deficit in tobacco plants over-expressing trans-zeatin Oglucosyltransferase gene under $35 S$ or SAG12 promoters. Plant Cell Environ 2008, 31(3):341-353.

92. Werner T, Nehnevajova E, Kollmer I, Novak O, Strnad M, Kramer U, Schmulling T: Root-specific reduction of cytokinin causes enhanced root growth, drought tolerance, and leaf mineral enrichment in Arabidopsis and tobacco. Plant Cell 2010.

93. Jaillais $Y$, Chory J: Unraveling the paradoxes of plant hormone signaling integration. Nat Struct Mol Biol 2010, 17(6):642-645.

94. Nemhauser JL, Hong F, Chory J: Different plant hormones regulate similar processes through largely nonoverlapping transcriptional responses. Cell 2006, 126(3):467-475.

95. Conconi A, Miquel M, Browse JA, Ryan CA: Intracellular levels of free linolenic and linoleic acids increase in tomato leaves in response to wounding. Plant Physiol 1996, 111(3):797-803.

96. Reddy PS, Kumar TC, Reddy MN, Sarada C, Reddanna P: Differential formation of octadecadienoic acid and octadecatrienoic acid products in control and injured/infected potato tubers. Biochim Biophys Acta 2000, 1483(2):294-300.

97. Blee E: Impact of phyto-oxylipins in plant defense. Trends Plant Sci 2002, 7(7):315-322.

98. Siedow JN: Plant lipoxygenase: Structure and function. Annu Rev Plant Phys 1991, 42(1):145-188.

99. Noordermeer MA, Veldink GA, Vliegenthart JF: Fatty acid hydroperoxide lyase: a plant cytochrome p450 enzyme involved in wound healing and pest resistance. Chembiochem 2001, 2(7-8):494-504.

100. Nemchenko A, Kunze S, Feussner I, Kolomiets M: Duplicate maize 13lipoxygenase genes are differentially regulated by circadian rhythm, cold stress, wounding, pathogen infection, and hormonal treatments. J Exp Bot 2006, 57(14):3767-3779.

101. Swindell WR: The association among gene expression responses to nine abiotic stress treatments in Arabidopsis thaliana. Genetics 2006, 174(4):1811-1824.

102. Almagro L, Gomez Ros LV, Belchi-Navarro S, Bru R, Ros Barcelo A, Pedreno MA: Class III peroxidases in plant defence reactions. J Exp Bot 2009, 60(2):377-390.

103. Alvarez ME: Salicylic acid in the machinery of hypersensitive cell death and disease resistance. Plant Mol Biol 2000, 44(3):429-442.

104. De Torres Zabala M, Bennett MH, Truman WH, Grant MR: Antagonism between salicylic and abscisic acid reflects early host-pathogen conflict and moulds plant defence responses. Plant J 2009, 59(3):375-386. 
105. Gémes K, Poór P, Horváth E, Kolbert Z, Szopkó D, Szepesi Á, Tari I: Crosstalk between salicylic acid and $\mathrm{NaCl}$-generated reactive oxygen species and nitric oxide in tomato during acclimation to high salinity. Physiol Plantarum 2011.

106. Jung C, Lyou SH, Yeu S, Kim MA, Rhee S, Kim M, Lee JS, Choi YD, Cheong JJ: Microarray-based screening of jasmonate-responsive genes in Arabidopsis thaliana. Plant Cell Rep 2007, 26(7):1053-1063.

107. Robert-Seilaniantz A, Navarro L, Bari R, Jones JD: Pathological hormone imbalances. Curr Opin Plant Biol 2007, 10(4):372-379.

108. Eissenstat DM, Caldwell MM: Invasive root growth into disturbed soil of two tussock grasses that differ in competitive effectiveness. Funct Ecol 1989, , 3: 345-353.

109. Sengupta D, Kannan M, Reddy AR: A root proteomics-based insight reveals dynamic regulation of root proteins under progressive drought stress and recovery in Vigna radiata (L.) Wilczek. Planta 2011.

110. Smucker AJM: Soil environmental modifications of root dynamics and measurement. Annu Review Phytopathol 1993, , 31: 191-216.

111. Al-Ghazi $Y$, Muller B, Pinloche $S$, Tranbarger TJ, Nacry P, Rossignol M, Tardieu F, Doumas P: Temporal responses of Arabidopsis root architecture to phosphate starvation: evidence for the involvement of auxin signalling. Plant, Cell \& Environ 2003, 26(7):1053-1066.

112. Jain A, Poling MD, Karthikeyan AS, Blakeslee JJ, Peer WA, Titapiwatanakun B, Murphy AS, Raghothama KG: Differential effects of sucrose and auxin on localized phosphate deficiency-induced modulation of different traits of root system architecture in Arabidopsis. Plant Physiol 2007, 144(1):232-247.

113. Lopez-Bucio J, Hernandez-Abreu E, Sanchez-Calderon L, Nieto-Jacobo MF, Simpson J, Herrera-Estrella L: Phosphate availability alters architecture and causes changes in hormone sensitivity in the Arabidopsis root system. Plant Physiol 2002, 129(1):244-256.

114. Miura K, Lee J, Gong Q, Ma S, Jin JB, Yoo CY, Miura T, Sato A, Bohnert HJ, Hasegawa PM: SIZ1 regulation of phosphate starvation-induced root architecture remodeling involves the control of auxin accumulation. Plant Physiol 2011, 155(2):1000-1012.

115. Nacry P, Canivenc G, Muller B, Azmi A, Van Onckelen H, Rossignol M, Doumas $P$ : A role for auxin redistribution in the responses of the root system architecture to phosphate starvation in Arabidopsis. Plant Physiol 2005, 138(4):2061-2074.

116. Perez-Torres CA, Lopez-Bucio J, Cruz-Ramirez A, Ibarra-Laclette E, Dharmasiri S, Estelle M, Herrera-Estrella L: Phosphate availability alters lateral root development in Arabidopsis by modulating auxin sensitivity via a mechanism involving the TIR1 auxin receptor. Plant Cell 2008, 20(12):3258-3272.

117. Shinozaki K, Yamaguchi-Shinozaki K: Molecular responses to dehydration and low temperature: Differences and cross-talk between two stress signaling pathways. Curr Opin Plant Biol 2000, 3(3):217-223.

118. Yamaguchi-Shinozaki K, Shinozaki K: A novel cis-acting element in an Arabidopsis gene is involved in responsiveness to drought, lowtemperature, or high-salt stress. Plant Cell 1994, 6(2):251-264.

119. Baker SS, Wilhelm KS, Thomashow MF: The 5'-region of Arabidopsis thaliana cor15a has cis-acting elements that confer cold-, drought- and ABA-regulated gene expression. Plant Mol Biol 1994, 24(5):701-713.

120. Jiang $C$, lu $B$, Singh J: Requirement of a CCGAC cis-acting element for cold induction of the BN115 gene from winter Brassica napus. Plant Mol Biol 1996, 30(3):679-684.

121. Lescot $M$, Dehais $P$, Thijs $G$, Marchal $K$, Moreau $Y$, Van de Peer $Y$, Rouze $P$, Rombauts S: PlantCARE, a database of plant cis-acting regulatory elements and a portal to tools for in silico analysis of promoter sequences. Nucleic Acids Res 2002, 30(1):325-327.

122. Rombauts $S$, Dehais $P$, Van Montagu M, Rouze P: PlantCARE, a plant cisacting regulatory element database. Nucleic Acids Res 1999, 27(1):295-296.

123. Higo K, Ugawa Y, Iwamoto M, Korenaga T: Plant cis-acting regulatory DNA elements (PLACE) database: 1999. Nucleic Acids Res 1999, 27(1):297-300.

124. Higo K, Ugawa Y, Iwamoto M, Higo H: PLACE: a database of plant cisacting regulatory DNA elements. Nucleic Acids Res 1998, 26(1):358-359.

125. Dietz KJ, Vogel MO, Viehhauser A: AP2/EREBP transcription factors are part of gene regulatory networks and integrate metabolic, hormonal and environmental signals in stress acclimation and retrograde signalling. Protoplasma 2010, 245(1-4):3-14.

126. Hoekstra FA, Golovina EA, Buitink J: Mechanisms of plant desiccation tolerance. Trends Plant Sci 2001, 6(9):431-438.
127. Iordachescu M, Imai R: Trehalose biosynthesis in response to abiotic stresses. J Integr Plant Biol 2008, 50(10):1223-1229.

128. Livingston DP, Hincha DK, Heyer AG: Fructan and its relationship to abiotic stress tolerance in plants. Cell Mol Life Sci 2009, 66(13):2007-2023.

129. Oliver MJ, Cushman JC, Koster KL: Dehydration tolerance in plants. In Plant Stress Tolerance. Volume 639. Edited by: Sunkar R. Humana Press; 2010:3-24

130. Wingler A, Roitsch T: Metabolic regulation of leaf senescence: Interactions of sugar signalling with biotic and abiotic stress responses. Plant Biol 2008, 10:50-62

131. Uno Y, Furihata T, Abe H, Yoshida R, Shinozaki K, Yamaguchi-Shinozaki K: Arabidopsis basic leucine zipper transcription factors involved in an abscisic acid-dependent signal transduction pathway under drought and high-salinity conditions. Proc Natl Acad Sci USA 2000, 97(21):11632-11637.

132. Kim S, Kang Jy, Cho DI, Park JH, Kim SY: ABF2, an ABRE-binding bZIP factor, is an essential component of glucose signaling and its overexpression affects multiple stress tolerance. Plant J 2004, 40(1):75-87.

133. Huang P, Chung MS, Ju HW, Na HS, Lee DJ, Cheong HS, Kim CS: Physiological characterization of the Arabidopsis thaliana Oxidationrelated Zinc Finger 1, a plasma membrane protein involved in oxidative stress. J Plant Res 2010.

134. Pérez-Rodríguez $P$, Riaño-Pachón DM, Corrêa LGG, Rensing SA, Kersten $B$, Mueller-Roeber B: PInTFDB: updated content and new features of the plant transcription factor database. Nucleic Acids Res 2010, 38(suppl 1): D822-D827.

135. Riaño-Pachón D, Ruzicic S, Dreyer I, Mueller-Roeber B: PInTFDB: an integrative plant transcription factor database. BMC Bioinformatics 2007, 8(1):42.

136. Guo AY, Chen X, Gao G, Zhang H, Zhu QH, Liu XC, Zhong YF, Gu X, He K, Luo J: PlantTFDB: a comprehensive plant transcription factor database. Nucleic Acids Res 2008, 36(suppl 1):D966-D969.

137. He K, Guo AY, Gao G, Zhu QH, Liu XC, Zhang H, Chen X, Gu X, Luo J: Computational identification of plant transcription factors and the construction of the PlantTFDB database. In Computational Biology of Transcription Factor Binding. Volume 674. Edited by: Ladunga I. Humana Press; 2010:351-368.

138. Zhang $H$, Jin J, Tang L, Zhao Y, Gu X, Gao G, Luo J: PlantTFDB 2.0: update and improvement of the comprehensive plant transcription factor database. Nucleic Acids Res 2011, 39(suppl 1):D1114-D1117.

139. Yilmaz A, Nishiyama MY, Fuentes BG, Souza GM, Janies D, Gray J, Grotewold E: GRASSIUS: A platform for comparative regulatory genomics across the grasses. Plant Physiol 2009, 149(1):171-180.

140. Sharoni AM, Nuruzzaman M, Satoh K, Shimizu T, Kondoh H, Sasaya T, Choi IR, Omura T, Kikuchi S: Gene structures, classification and expression models of the AP2/EREBP transcription factor family in rice. Plant Cell Physiol 2011, 52(2):344-360.

141. Karaba A, Dixit S, Greco R, Aharoni A, Trijatmiko KR, Marsch-Martinez N, Krishnan A, Nataraja KN, Udayakumar M, Pereira A: Improvement of water use efficiency in rice by expression of HARDY, an Arabidopsis drought and salt tolerance gene. Proc Natl Acad Sci USA 2007, 104(39):15270-15275.

142. Abogadallah GM, Nada RM, Malinowski R, Quick P: Overexpression of HARDY, an AP2/ERF gene from Arabidopsis, improves drought and salt tolerance by reducing transpiration and sodium uptake in transgenic Trifolium alexandrinum L. Planta 2011.

143. Zhang G, Chen M, Li L, Xu Z, Chen X, Guo J, Ma Y: Overexpression of the soybean GmERF3 gene, an AP2/ERF type transcription factor for increased tolerances to salt, drought, and diseases in transgenic tobacco. J Exp Bot 2009, 60(13):3781-3796.

144. Lenka SK, Lohia B, Kumar A, Chinnusamy V, Bansal KC: Genome-wide targeted prediction of $A B A$ responsive genes in rice based on overrepresented cis-motif in co-expressed genes. Plant Mol Biol 2009, 69(3):261-271.

145. Lenka SK, Katiyar A, Chinnusamy V, Bansal KC: Comparative analysis of drought-responsive transcriptome in Indica rice genotypes with contrasting drought tolerance. Plant Biotechnol J 2010.

146. Youens-Clark K, Buckler E, Casstevens T, Chen C, Declerck G, Derwent P, Dharmawardhana P, Jaiswal P, Kersey P, Karthikeyan AS, et al: Gramene database in 2010: updates and extensions. Nucleic Acids Res 2010. 
147. Choi H, Hong J, Ha J, Kang J, Kim SY: ABFs, a family of ABA-responsive element binding factors. J Biol Chem 2000, 275(3):1723-1730.

148. He Y, Gan S: Identical promoter elements are involved in regulation of the OPR1 gene by senescence and jasmonic acid in Arabidopsis. Plant Mol Biol 2001, 47(5):595-605.

149. Kirsch C, Takamiya-Wik M, Schmelzer E, Hahlbrock K, Somssich IE: A novel regulatory element involved in rapid activation of parsley ELI7 gene family members by fungal elicitor or pathogen infection. Mol Plant Pathol 2000, 1(4):243-251.

150. Zhang H, Liang W, Yang X, Luo X, Jiang N, Ma H, Zhang D: Carbon Starved Anther encodes a MYB domain protein that regulates sugar partitioning required for rice pollen development. Plant Cell 2010, 22(3):672-689.

151. Piechulla B, Merforth N, Rudolph B: Identification of tomato Lhc promoter regions necessary for circadian expression. Plant Mol Biol 1998, 38(4):655-662.

152. Dubouzet JG, Sakuma Y, Ito Y, Kasuga M, Dubouzet EG, Miura S, Seki M, Shinozaki K, Yamaguchi-Shinozaki K: OsDREB genes in rice, Oryza sativa L., encode transcription activators that function in drought-, high-salt- and cold-responsive gene expression. Plant J 2003, 33(4):751-763.

153. Qin F, Sakuma Y, Li J, Liu Q, Li YQ, Shinozaki K, Yamaguchi-Shinozaki K: Cloning and functional analysis of a novel DREB1/CBF transcription factor involved in cold-responsive gene expression in Zea mays L. Plant Cell Physiol 2004, 45(8):1042-1052.

154. Nagao RT, Goekjian VH, Hong JC, Key JL: Identification of protein-binding DNA sequences in an auxin-regulated gene of soybean. Plant Mol Biol 1993, 21(6):1147-1162

155. Pastuglia M, Roby D, Dumas C, Cock JM: Rapid induction by wounding and bacterial infection of an $\mathrm{S}$ gene family receptor-like kinase gene in Brassica oleracea. Plant Cell 1997, 9(1):49-60.

156. Young MD, Wakefield MJ, Smyth GK, Oshlack A: Gene ontology analysis for RNA-seq: accounting for selection bias. Genome Biol 2010, 11(2):R14.

157. Du Z, Zhou X, Ling Y, Zhang Z, Su Z: agriGO: a GO analysis toolkit for the agricultural community. Nucleic Acids Res 2010, 38 Suppl:W64-70.

158. Cline MS, Smoot M, Cerami E, Kuchinsky A, Landys N, Workman C, Christmas R, Avila-Campilo I, Creech M, Gross B, et al: Integration of biological networks and gene expression data using Cytoscape. Nat Protoc 2007, 2(10):2366-2382.

159. Shannon P, Markiel A, Ozier O, Baliga NS, Wang JT, Ramage D, Amin N, Schwikowski B, Ideker T: Cytoscape: A software environment for integrated models of biomolecular interaction networks. Genome Res 2003, 13(11):2498-2504.

doi:10.1186/1471-2164-12-514

Cite this article as: Dugas et al:: Functional annotation of the transcriptome of Sorghum bicolor in response to osmotic stress and abscisic acid. BMC Genomics 2011 12:514.

\section{Submit your next manuscript to BioMed Central and take full advantage of:}

- Convenient online submission

- Thorough peer review

- No space constraints or color figure charges

- Immediate publication on acceptance

- Inclusion in PubMed, CAS, Scopus and Google Scholar

- Research which is freely available for redistribution

Submit your manuscript at www.biomedcentral.com/submit 